Revista lus et Praxis, Año 17, No 1, 2011, pp. 81 - 118

ISSN 0717 - 2877

Universidad de Talca - Facultad de Ciencias Jurídicas y Sociales

"Jurisdicción Constitucional y Derechos Fundamentales.

Aspectos a destacar en el contexto de la discusión española" Luis Villacorta Mancebo

\title{
JURISDICCIÓN CONSTITUCIONAL Y DERECHOS FUNDAMENTALES. ASPECTOS A DESTACAR EN EL CONTEXTO DE LA DISCUSIÓN ESPAÑOLA*
}

\author{
Fundamental RIGHTS AND CONSTITUCIONAL JURISDITION. SOME FEATURES TO \\ HIGHTLIGHT IN THE SPANISH CONTEXT DISCUSSION
}

LUis Villacorta ManCeBo*

\begin{abstract}
RESUMEN
Los Derechos Fundamentales constituyen el sistema de valores en orden a la pervivencia de la comunidad. Ahora bien, la evolución más significativa de la teoría de los Derechos Fundamentales procede del reconocimiento, junto a la garantía individual concreta, de la dimensión jurídico-objetiva iusfundamental. El nuevo planteamiento ha resultado esencial para el reforzamiento de los Derechos Fundamentales, a cuyo respecto surge para el Estado Social no sólo una prohibición de exceso sino también una prohibición de omisión. El Tribunal Constitucional español reconoce desde la Sentencia 25/1981 (en adelante: STC) el doble carácter de los Derechos Fundamentales, esto es, su consideración en cuanto derechos públicos subjetivos y atendiendo a su naturaleza de elementos esenciales de un ordenamiento objetivo de la comunidad. Debido a su eficacia normativa inmediata y al carácter esencial aludido, su vigencia y garantía afecta de modo esencial a la legitimidad del Estado; ello explica que buena parte de los mismos reciban protección jurisdiccional privilegiada por parte del Tribunal Constitucional. Era poco probable la rápida imposición de los Derechos Fundamentales en España sin la garantía de un Tribunal Constitucional comprometido ante la nueva Constitución.

ABSTRACT

Fundamental Rights consist of a system of values in order to guarantee the survival of the community. However, the most significant evolution of the Fundamental Rights theory begins with the acknowledgement, together with the concrete individual guarantee, of a legal-objective dimension. This new approach has been essential for reinforcing Fundamental rights, in which respect for the social state there appears to be not only the prohibition of excess as well as that of omission. The Spanish Constitutional Tribunal acknowledges under the 25/1981 sentence the double character of Fundamental Rights, that is, its consideration as far as subjective public rights, and as essential elements for the objective order of the community, due to its immediate regulatory efficiency, its validity and guaranty affects essentially the legitimacy of the State; this explains that the main part of the same receives privileged
\end{abstract}

\footnotetext{
*Trabajo recibido el 2 de octubre de 2010 y aprobado el 28 de marzo de 2011.

** Catedrático de Derecho Constitucional, Universidad de Cantabria (España). Correo electrónico: luis. villacorta@unican.es.
} 
jurisdictional protection from the Constitutional Tribunal. The imposition of the Fundamental Rights in Spain was unlikely without the guarantee of a Constitutional Tribunal being committed to the new Constitution.

PALABRAS CLAVE

Derechos Fundamentales, Derechos Objetivos, Derechos Subjetivos, Tribunal Constitucional

KEY WORDS

Fundamental Rights, Objective Rights, Subjective Rights, Constitutional Tribunal

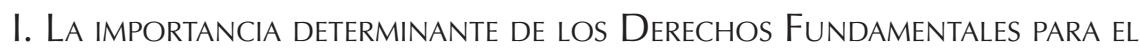
CONSTITUCIONALISMO DEMOCRÁTICO

La vigente Constitución española de 1978 al ocuparse de los Derechos Fundamentales y su haz de garantías protectoras, incorpora programas normativos en cuyo empleo han de tener especial cuidado los juristas pero también los no juristas, toda vez que, una vez integrados con sus ámbitos normativos respectivos, constituyen un Derecho para y de la comunidad política; en definitiva, porque estamos de acuerdo con $R$. Smed y su comprensión de los Derechos Fundamentales, como el "derecho profesional y personal del ciudadano".

$\mathrm{Si}$ recordamos, en el famoso pasaje comparativo debido al precitado autor entre el ciudadano y el bourgeois, los Derechos Fundamentales terminan adquiriendo el carácter de programa, principios e instrumentos normativos -la tarea integradora del Derecho-, en orden a la consecución de la integración nacional': "en la línea del compromiso que suponen este programa y estos principios, el pueblo alemán se ha unido en la Constitución de Weimar en la realización de este programa, el Estado de la Constitución de Weimar ha de encontrar su contenido para siempre, ha de realizarse". La trágica ruptura inmediata con tales principios y filosofía de vida nos es bien conocida y, por ello, en el inicio de la segunda postguerra, como reconoce $K$. Hesse, se observaría que la historia política e intelectual de otros estados occidentales europeos había ido creando una cultura política que podía prescindir en cierto modo de un sistema de garantías jurídicas tan sofisticado y perfecto como el que necesariamente debieron articular los redactores de la Ley Fundamental de Bonn para la protección de los Derechos Fundamentales, algo que también puede afirmarse por referencia a la situación histórica en la que nace el Estado democrático español en 1978. Ciertamente, las previsiones normativas incluidas en la Grundgesetz acerca de los Derechos Fundamentales carecían de precedentes tanto histórica como comparativamente, esto es, la decidida opción de implantar una fuerte y extensa tutela jurídica de los derechos con objeto de lograr su plena eficacia vinculante,

${ }^{1}$ Programa de integración normativo que invita al dinámico y progresivo desenvolvimiento a través de la evolución de las circunstancias políticas y sociales. 
y a modo de reacción frente a las gravísimas violaciones sufridas por los mismos con ocasión de los crímenes masivos del régimen nacional-socialista. No en vano, si nos hacemos eco de la elocuente manifestación en sede constituyente del diputado Carlo Schmidt, recordada en varias oportunidades por la doctrina constitucional alemana, los Derechos Fundamentales implicaban en aquella circunstancia histórico-concreta la "decisión de formalizar la vida del Estado orientándola en una dirección determinada".

Pues bien, la regulación de los Derechos Fundamentales en el vigente texto constitucional español registra esencialmente al efecto la influencia de lo dispuesto por la Ley Fundamental de Bonn, y ya se sabe que esta última es considerada la Constitución de los Derechos Fundamentales, habiendo sido desarrollada e interpretada expansivamente siempre en función de la efectividad de los mismos, algo que se ha procurado también en España. $Y$ en sentido similar a lo acontecido en Alemania, conforme se desprende de la comparación entre ambos ordenamientos, la Constitución Española (CE) dispuso como bases del orden constitucional, además de la Democracia Social y el Estado de Derecho, y con carácter previo, la garantía de la dignidad humana en cuanto "germen y núcleo" de unos Derechos Fundamentales "que le son inherentes"2, las libertades garantizadas por los Derechos Fundamentales en su multiplicidad de dimensiones, en fin, el principio de igualdad (asimismo, entendido como Derecho Fundamental). A partir de las anteriores premisas, se comprende la vinculatoriedad reforzada, la reserva de ley y la garantía del contenido esencial de los Derechos Fundamentales como límite infranqueable de cada derecho individualmente considerado ${ }^{3}$, en su carácter de instituciones jurídicas previs-

${ }^{2}$ STC 53/1985, de 11 de abril.

${ }^{3}$ La sentencia del Tribunal Constitucional español que puede considerarse clásica sobre la cuestión es la 11/1981, de 8 de abril. Conforme a la misma, tal contenido "es el conjunto de facultades o posibilidades de actuación necesarias para que el derecho sea recognoscible como perteneciente al tipo descrito y sin las cuales deja de pertenecer a este tipo y tiene que pasar a convertirse en otro, desnaturalizándose, por decirlo así. Todo ello, referido al momento histórico de que en cada caso se trata y a las condiciones inherentes a las sociedades democráticas cuando se trate de derechos constitucionales"; expresado de otro modo, abarca aquella parte "del contenido del derecho que es absolutamente necesaria para que los intereses jurídicamente protegibles, que dan vida al derecho, resulten real, concreta y efectivamente protegidos. De este modo, se rebasa o se desconoce el contenido esencial cuando el derecho queda sometido a limitaciones que lo hacen impracticable, lo dificultan más allá de lo razonable o lo despojan de la necesaria protección".

Y para tratar de aproximarse de algún modo a la idea de contenido esencial, el Tribunal Constitucional español señala dos posibles caminos: "El primero es tratar de acudir a lo que se suele Ilamar la naturaleza jurídica o el modo de concebir o de configurar cada derecho" (tesis de la recognoscibilidad); y "El segundo posible camino para definir el contenido esencial de un derecho consiste en tratar de buscar lo que una importante tradición ha llamado los intereses jurídicamente protegidos como núcleo y médula de los derechos subjetivos. Se puede entonces hablar de una esencialidad del contenido del derecho para hacer referencia a aquella parte del contenido del derecho que es absolutamente necesaria para que los intereses jurídicamente protegibles, que dan vida al derecho, resulten real, 
tas todas ellas por el programa normativo del Art. 53.1 de la CE. Asimismo, se complementa la protección íntegra de los Derechos Fundamentales al añadirse a las anteriores garantías una especial protección jurisdiccional por medio, tanto de la jurisdicción ordinaria como por la constitucional (Arts. 53.2 y 161.1.b CE). De este modo, a decir de significativos sectores doctrinales, se ha llevado a sus últimas consecuencias la idea kelseniana de que no basta la mera atribución de derechos al individuo, sino que resulta necesaria, al mismo tiempo, la articulación de procedimientos técnico-jurídicos, en virtud de los cuales se le permita reaccionar jurisdiccionalmente contra cualquier violación de su status jurídico subjetivo ${ }^{4}$.

En este sentido, en la España de 1978, en mayor medida aún que en la Alemania de 1949 y debido a los avatares de nuestra frustrante historia constitucional, ante el vacío cultural (en el sentido de realización de la cultura constitucional finalista) y político, los Derechos Fundamentales resultaban, asimismo, obligados a cumplir una función sustitutiva. Realmente, la Constitución española de 1978 no podía limitarse a conformar un texto legal supremo que estableciera meramente un Derecho especial desde el punto de vista técnico, esto es, competencias, procedimientos y límites a los poderes constituidos, sino que necesitaba proclamar un sistema de valores de directa aplicación, integrado por el sistema de Derechos Fundamentales ${ }^{5}$; un sistema cultural que ejerciera una función objetivamente integradora y legitimadora, sin el cual ninguna comunidad política democrática puede vivir. En efecto, según hemos apuntado, hace ya un siglo consideró $R$. Smend que los Derechos Fundamentales contenían los factores objetivos que permitían la integración nacional, por ser expresivos de un sistema cultural de valores indicativo del sentido de la vida estatal conforme a la Constitución. Y H. Heller, en la concepción del Estado que le es propia, alentada desde una perspectiva de carácter normativo, pero

concreta y efectivamente protegidos. De este modo, se rebasa o se desconoce el contenido esencial cuando el derecho queda sometido a limitaciones que lo hacen impracticable, lo dificultan más allá de lo razonable o lo despojan de la necesaria protección".

En fin, según concluye, los dos caminos propuestos para tratar "de definir lo que puede entenderse por "contenido esencial" de un derecho subjetivo no son alternativos, ni menos todavía antitéticos, sino que, por el contrario, se pueden considerar como complementarios, de modo que, al enfrentarse con la determinación del contenido esencial de cada concreto derecho pueden ser conjuntamente utilizados para contrastar los resultados a los que por una u otra vía pueda llegarse".

${ }^{4}$ Como apuntara el propio Hans Kelsen, "la esencia del derecho subjetivo que es más que el simple reflejo de un deber jurídico, consistente en que una norma jurídica atribuya a una persona el poder jurídico de impugnar el incumplimiento de un deber jurídico mediante una acción judicial", KelseN, Hans, Reine Rechtslehre: Einleitung in die rechtswissenschaftliche Problematik, $2^{a}$ Edición, Franz Deuticke, Wien, 1960, p. 150.

${ }^{5}$ Los Derechos Fundamentales y libertades públicas reconocidos por la Constitución española, dirá entre otras y en este sentido, la STC 39/1983, de 17 de mayo, son de aplicación directa, sin que sea necesario en orden a su efectividad su desarrollo legislativo (Art. 53.1 de la CE). 
acompañada de una simultánea comprensión del pluralismo político y social, además de subrayar el carácter de compromisos jurídico-formales propio de los Derechos Fundamentales, apunta a su definición como "formas de la vida social que habían penetrado la realidad cultural, política y económica" ${ }^{\prime 6}$. En esta línea, señala la STC 25/1981, de 14 de julio, la Constitución española proclama "un orden de valores que tiene una específica significación para el establecimiento y fundamentación de un orden de convivencia política general".

Por ello, debido al especial trasfondo de la historia político-constitucional española, los Derechos Fundamentales adquirirían en 1978 el significado de constituir la base espiritual y material del nuevo orden estatal democrático que se pretendía instaurar, en consonancia con el ámbito cultural de las actuales democracias pluralistas al que se accedía, y a la búsqueda ya, asimismo, de la Europa unificada. De ahí que el Art. 10.1 de la CE reconozca cristalinamente tal horizonte espiritual vital, y después de expresar que la ratio última del Estado constituido descansa en la realización plena de la dignidad humana en cuanto "valor espiritual y moral inherente a la persona" ${ }^{17}$, así como el logro del libre desarrollo de la personalidad, termina reconociendo que son precisamente los Derechos Fundamentales el concreto fundamento constitutivo "del orden político y de la paz social". Perspectiva que refuerza la vocación universalista expresada por el texto del Art. 10.2 de la CE, a partir del cual existe la obligación de interpretar los preceptos constitucionales a través de los cuales se reconocen los Derechos Fundamentales "de conformidad con la Declaración Universal de Derechos Humanos y los tratados y acuerdos internacionales sobre las mismas materias ratificados por España".

Por tanto, no es mera casualidad la importancia adquirida por los Derechos Fundamentales entre nosotros; si bien, tal importancia real y determinante corre el riesgo de exagerarse con facilidad y llegar con ello a situarnos en una especie de dimensión "teológica", ante lo que es preciso ser precavidos, toda vez que el exceso nos colocaría ante otra situación distinta (e invasora en todos sus aspectos) de la conveniente jurídica y políticamente. Aun cuando, verdaderamente, resulta conveniente despojar a los Derechos Fundamentales (su contenido jurídico y garantías) del halo de misterio con el que a veces se presenta por algunas corrientes iusfilosóficas, puede ser, por el contrario, inconveniente la renuncia a su carácter material y formalmente esencialista, esto es, "humanamente trascendental" en sentido material.

${ }^{6}$ Incluso el Carl Schmitt weimariano hablaría para referirse a los Derechos Fundamentales de "contenidos axiológicos", "instituciones sagradas", y aludiría a su valor de "fundamentos del estado", Sснмітт, Carl, Legalität und Legitimität, $7^{\mathrm{a}}$ Edición, Duncker \& Humblot, Berlín, 1998.

${ }^{7}$ STC 53/1985, de 11 de abril. 
De esta suerte, toda vez que queda mucho por decir tanto desde el punto de vista jurídico-estatal como democrático, sigue siendo tarea urgente e ineludible proseguir en la construcción de una teoría material de los Derechos Fundamentales constitucionalmente adecuada y, en consecuencia, dinámica y acompasada al tiempo, pero más que para justificar su fundamentación, con el objeto de optimizar la realización de los mismos en su diversidad de dimensiones. Por nuestra parte, no vamos a pasar ahora revista a las diversas teorías más importantes de carácter general desarrolladas ni tampoco a las construidas específicamente con ocasión del análisis de cada particular derecho fundamental, por cuanto las primeras son conocidas y las segundas (lógicamente, en concordancia con las primeras), debido al esfuerzo hercúleo que tal tarea supondría, quedan fuera de nuestro alcance y actual propósito. No obstante, sí queremos incidir brevemente en un aspecto, y es que, por de pronto, rechazamos categóricamente, debido a la ruda simplificación a veces apuntada pero impedida precisamente por su doble carácter, aquellas tesis que contemplan los Derechos Fundamentales orientados desde una perspectiva formal exclusivamente "hacia" los individuos, en el sentido de límites a la intervención estatal y derechos de defensa -Abwehrrechte. Semejante perspectiva pudiera concordar con una visión de los derechos en la mejor de las hipótesis de carácter liberal, cual fuera el caso de un E. Forsthoff, por ejemplo, quien paradójicamente viera en las corrientes institucionales la resurrección del privilegio. O más modernamente y, claro está, sin la precomprensión autoritaria del anterior, en los términos de la única perspectiva de los Derechos (la liberal) considerada útil, como sucede con Chr. Hillgruber ${ }^{8}$; perspectivas seguidas más o menos conscientemente por sectores doctrinales españoles. Efectivamente, valorando desde luego la importancia decidida de la vertiente subjetiva, consideramos imprescindible situar a los Derechos Fundamentales en el campo de las fuerzas sociales, como Derechos de status jurídico-material, tal como son comprendidos en sentido similar por K. Hesse y F. Müller.

De otra parte, puesto que en el Estado social y democrático se trata siempre de lograr la libertad real para todos a modo de horizonte vital, la dogmática de los Derechos Fundamentales requiere, asimismo, analizar con especial delicadeza (y decisión) la temática de la eficacia y protección de los Derechos sociales (fundamentales o no, tampoco podemos ahora detenernos en ello), procurando explotar al máximo las posibilidades jurídicas ofrecidas por el programa normativo constitucional respectivo. Se persigue con ello la finalidad de ir haciendo realmente efectivos mandatos constitucionales encaminados a dotar de los correspondientes presupuestos materiales a quienes carentes de los mismos se

${ }^{8}$ Puede verse su conocida y contestada monografía Hillgruber, Christian, Der Schutz des Menschen vor sich selbst, Vahlen, München, 1992. 
hallan incapaces de usar las libertades garantizadas por los Derechos Fundamentales (incapacidad subjetiva). Y entre tales mandatos, citamos a modo de ejemplo y por todos, como con frecuencia e inevitablemente se hace la doctrina científica española al tratar estos temas, el recogido por el texto del Art. 9.2 de la CE: "Corresponde a los poderes públicos promover las condiciones para que la libertad y la igualdad del individuo y de los grupos en que se integra sean reales y efectivas; remover los obstáculos que impidan o dificulten su plenitud y facilitar la participación de todos los ciudadanos en la vida política, económica, cultural y social". Porque, si seguimos a Cascajo Castro ${ }^{9}$, la cristalización en el texto constitucional español de los Derechos sociales, básicamente recogidos en el capítulo tercero del Título I -Arts. 39 a 52 de la CE- bajo la denominación "Principios rectores de la política social y económica", supone, de una parte, la mejor muestra superadora de la clásica tesis de los derechos públicos subjetivos, y de otra, junto a la admisión también de una eventual "traducción en términos de figuras jurídicas subjetivas", la posibilidad de afirmar que los Derechos sociales han de ser, asimismo, entendidos "como un programa constitucional de distribución de bienes, que se realiza mediante el equilibrio de intereses públicos, colectivos y privados". Si de verdad se aspira a la plena efectividad del nuevo pacto social o actual pacto constitucional -Verfassungsvertrag-, para que estos derechos ganen fuerza vinculante e intensidad normativa, la aplicación del Art. 53.3 de la CE no puede llevarse a cabo de manera aislada, algo que pudiera incluso pensarse hace el Tribunal Constitucional español en alguna oportunidad, caso de la STC 65/1997, de 30 de diciembre. Con todo, recuerda en la misma el Alto Tribunal la libertad del legislador en su valoración del contexto social y económico, lo que le permite establecer "el nivel y condiciones de las prestaciones a efectuar o las modificaciones para adaptarlas a las necesidades del momento"; jurisprudencia jalonada de modo interesado desde cierta doctrina iuspublicista, y a cuya conclusión de la licitud de la interpretación aislada del Art. 53.3 de la CE se llega por tal "doctrina" a través de un mero "sobrevuelo". Sin embargo, la mayoría de la doctrina científica española conoce las técnicas de la interpretación constitucional, y no pretende la hermenéutica aislada de precepto constitucional alguno, porque recuerda las exigencias de la interpretación sistemática, de la concordancia práctica, o el más discutible y holista principio de unidad constitucional, por ejemplo. De este modo, el enlace, entre otros, con el precitado Art. 9.2 de la CE resulta inevitable en la aplicación del respectivo derecho. Cuando el Tribunal Constitucional español habla de libertad del legislador, suponemos que lo hace (a cuya suposición se llega sin necesidad

${ }^{9}$ Quizá el autor que mayor partido ha sacado al precario programa normativo extraíble del texto lingüístico recogido por el Art. 53.3 de la CE, puede así verse CASCAJO CASTRO, José-Luis, La tutela constitucional de los derechos sociales, CEC, Madrid, 1988. 
de ser extraordinariamente perspicaces) desde la consideración del doble carácter de la Constitución en cuanto marco -Rahmenordung- para, y fundamento -Grundordnung- del ordenamiento. En este ámbito constitucionalmente lícito, el legislador puede ofrecer una diversidad amplia pero limitada de alternativas, ya que asimismo en materia de Derechos Fundamentales no todo está predeterminado desde la Constitución como a veces se insinúa, en cuanto ésta ampara un ámbito en el que caben diversas alternativas políticas de desarrollo, algo recordado frecuentemente por la jurisprudencia constitucional española. No cabe olvidar que unos Derechos Fundamentales sociales precarios en cuanto a su carácter normativo, terminan perjudicando la protección efectiva de los Derechos Fundamentales en su totalidad.

En consecuencia, la vinculación material de todos los poderes constituidos a los Derechos Fundamentales, términos inequívocamente recogidos por el Art. 53.1 de la CE, de modo que incluso al legislador le está vedado establecer otros límites distintos de los que sean inmanentes a una Constitución normativa de primacía ilimitada frente a cualquier otro acto estatal ${ }^{10}$, se explica atendiendo a su proyección en un doble sentido, aspecto al que vamos a aludir con brevedad. No obstante, con carácter previo, podemos recordar con E.W. Böckenförde la obligatoriedad impuesta por el principio estructural del Estado social y su influencia determinante en los Derechos Fundamentales, abriéndolos a nuevas técnicas prestacionales y procedimientos de garantía. En lógica consecuencia, se prohíbe que los poderes públicos autoricen -de manera singular el legislador- cualquier injerencia en los ámbitos iusfundamentales carente de base constitucional; de otro lado, se traduce en el mandato dirigido a lograr que los Derechos desplieguen plenamente su eficacia. En este contexto es donde realmente los Derechos Fundamentales terminan por convertirse en esa eficaz "palanca con la que el ciudadano puede hacer valer su libertad respecto a toda intervención injustificada, por lesiva del principio del Estado de Derecho, proveniente del Estado" (R. Wahl y J. Wieland).

\section{El doble carácter de los Derechos Fundamentales}

La cuestión del doble carácter pertenece desde los orígenes a la tradición de los Derechos Fundamentales, tal como en diversas oportunidades recordara con énfasis $K$. Hesse, autor que asimismo refiriera el hecho de que ya durante la República de Weimar da la cara la problemática del doble carácter, poniéndose sobre el tapete cuando con motivo de la aplicación de los preceptos iusfundamentales se mostró con particular crudeza la insuficiencia del método

${ }^{10}$ Así, la STC 11/1981, de 8 de abril, superadora de las vacilaciones previas que había mostrado la STC 5/1981, de 13 de febrero. 
formalista tradicional (vale decir, de la lógica formal propia de la ideología del positivismo metódico).

Sin embargo, debido a lo precario del constitucionalismo democrático europeo del periodo de entreguerras, es a partir del constitucionalismo de la segunda postguerra cuando la teoría del doble carácter se plantea radical y propiamente "originaria" para la teoría constitucional, recibiendo a partir de ahí un impulso definitivo y jurídicamente innovador. De esta suerte, por medio de un hecho concreto, como es la conocida Lüth-Urteil, de 15 de enero de 1958 (considerada por la doctrina científica europea una de las grandes decisiones en materia de Derechos Fundamentales), el Tribunal Constitucional Federal alemán aclararía con nitidez la cuestión de la doble naturaleza de los Derechos Fundamentales. Y lo haría en los siguientes términos: "la función primordial de los Derechos Fundamentales es, sin duda, la de proteger la esfera de libertad del individuo contra las intromisiones del poder público. Ello es consecuencia de la evolución histórica de la idea de Derechos Fundamentales, lo que se ha traducido en la incorporación de los Derechos Fundamentales en las constituciones de los distintos Estados". Si bien, tuvo al mismo tiempo especial empeño en dejar claro que con esta vertiente distaba de agotarse el contenido jurídico-constitutivo de los Derechos Fundamentales. Asimismo, desde la sentencia precitada, ha venido afirmando que la Ley Fundamental constituye un orden "axiológicamente neutro", sino un verdadero orden objetivo-material de valores fundamentales cuya clave de bóveda es la intangible dignidad humana, que irradia sus efectos incluso sobre las relaciones de los ciudadanos entre sí, expresando la intensificación de la "fuerza creadora" de los Derechos Fundamentales en el conjunto del ordenamiento ${ }^{11}$.

Pues bien, la cuestión del doble carácter ha sido resumida con singular acierto por E. G. Mahrenholz, quien considera que únicamente cabe hablar de derechos de defensa cuando éstos sean capaces de impedir intromisiones por la vía judicial, y seguidamente se interroga: "desde la lógica jurídica ¿de qué otra forma se puede establecer realmente una vinculación a los Derechos de defensa si no es considerándolos como normas objetivas?". Posteriormente, el Tribunal Constitucional Federal alemán ha reproducido una y otra vez la línea argumental contenida en la sentencia de $1958^{12}$, y proseguirá hablando

${ }^{11}$ La influencia de los planteamientos de Rudolf Smend en la sentencia ha sido objeto de constante debate por parte de la doctrina científica alemana, siendo probablemente mayoritaria la postura de quienes aceptan la aludida influencia en mayor o menor medida. Lo que sí resulta cierto es que los redactores del recurso de amparo Wilhem Hennis y Adolf Arndt citaron la ponencia de Rudol Smend, "Das Recht der freien Meinungsäußerung" (en VVStRL, Bd. 4, Berlin und Leipzig, Walter de Gruyter, 1928); 168, puede verse al efecto HeNNIS, Wilhelm, "Integration durch Verfassung?", Juristenzeitung, 1999, p. 492.

${ }^{12}$ En su primera sentencia relativa a la interrupción del embarazo, entre otras, formuló aún con mayor claridad, si cabe, la tesis del doble carácter de los Derechos Fundamentales: "de acuerdo con la juris- 
frecuentemente del contenido jurídico de los Derechos Fundamentales como normas objetivas ${ }^{13}$ : "Rechtsgehalt der Grundrechte als objetive Normen". Más precisamente, vendrá afirmando con continuidad que la tabla de Derechos Fundamentales integra toda ella un sistema de valores objetivos constitutivo en sí mismo de una unidad normativa, fundamento, a su vez, de la unidad normativa global de la Constitución; y al mismo tiempo, ha especificado la idea esencial de la teoría del doble carácter de los Derechos Fundamentales a través del establecimiento de varios principios centrales que, en este contexto, únicamente vamos a esbozar de forma sumaria.

\section{Principales consecuencias derivadas del doble CARÁCTER DE LOS DERECHOS FUNDAMENTALES}

A partir del reconocimiento junto a la vertiente subjetiva del carácter objetivo, dentro del vasto horizonte de problemas que de inmediato se abren, de los que nos referiremos sumariamente tan solo a algunos esenciales, forzoso es reconocer inicialmente que los Derechos Fundamentales despliegan, en primer término, un efecto de irradiación, proyectándose a todos los ámbitos jurídicos e incrementando de forma decidida su capacidad de incidencia en el ordenamiento jurídico en general. Y a la inversa, ello significa que el Ilamado Derecho legislado se presenta en muchos aspectos como Derecho constitucional concretizado $^{14}$. Expresado un poco más detenidamente, con el constitucionalismo democrático los Derechos Fundamentales adquirirán una eficacia distinta y más intensa, de irradiación al conjunto del ordenamiento jurídico: "han pasado a estar siempre presentes en el ordenamiento jurídico en su totalidad, a tener efectos no sólo bilaterales, sino erga omnes, adquiriendo un carácter absoluto" ( $R$. Wahl/J. Wieland). Debido a esta razón, en forma alguna pueden resultar extrañas las profundas implicaciones derivadas del carácter objetivo de los Derechos Fundamentales, dado que no solamente se toman como base de

prudencia permanente del Tribunal Constitucional Federal, las normas de Derechos Fundamentales no solamente contienen derechos subjetivos de defensa del individuo frente al Estado, sino que encarnan al mismo tiempo un orden objetivo de valores que, en tanto que decisión constitucional en materia de Derechos Fundamentales, es válido para todos los ámbitos del orden jurídico, y proporciona directrices generales y da impulsos a la legislación, a la administración y a la jurisdicción", BVerfGE (Sentencia del Tribunal Constitucional alemán) 39, 1 (41).

${ }^{13}$ En cuanto a la terminología empleada por el Bundesverfassungsgericht para referirse a la vertiente objetiva se observa que es variada; así, por ejemplo: objektive Wertordnung; verfassungsrechtliche Grundentscheidung; objektivrechtliche Wertentscheidung; Grundrechte als objektive Normen.

${ }^{14}$ Stern, Klaus; SAChs, Michael, Das Staatsrecht der Bundesrepublik Deutschland, vol. III/1, C.H. Beck, München, 1998, pp. 931 y ss. En este sentido, reconoce la STC 112/1989, de 19 de junio, la Constitución se convierte en "la parte general del ordenamiento jurídico", el cual debe ser interpretado en su totalidad "conforme a aquélla y en la medida más favorable a los Derechos Fundamentales". 
la verificación los derechos subjetivos clásicos sino también normas constitucionales jurídico-objetivas, tal es el caso, por ejemplo (e incluso), de las reglas de organización y procedimiento, esto es, el derecho organizativo o procesal necesario para la plena efectividad de los preceptos iusfundamentales. Por ello, estima $K$. Hesse, la idea del doble carácter tiene consecuencias de enorme calado, en cuanto los contenidos normativos de los Derechos Fundamentales permean la totalidad del ordenamiento jurídico del Estado constitucional, atendida sea esa su fuerza expansiva.

En segundo lugar y en lógica conexión con el referido aspecto anterior de su fuerza expansiva, los Derechos Fundamentales inciden naturalmente en el ámbito del Derecho privado. Cada Derecho Fundamental, en tanto que norma objetiva, desarrolla, asimismo, su contenido jurídico en el Derecho privado, y con esta singularidad se proyecta sobre la interpretación y la aplicación de las normas de Derecho privado. Como reconoce K. Hesse: "En virtud del mandato constitucional, el juez debe examinar si la aplicación de normas de Derecho civil afecta, en un caso concreto, a los Derechos Fundamentales. Si así fuera, estará obligado a interpretar y aplicar estas normas a la luz de los Derechos Fundamentales". Por consiguiente, vinculada también la jurisdicción a los Derechos Fundamentales tienen éstos un efecto ante terceros, siendo de menor importancia ahora la modalidad del mismo, sea indirecto o directo ${ }^{15}$; lo relevante va a resultar que el contenido de los Derechos Fundamentales debe

\footnotetext{
${ }^{15}$ El Tribunal Constitucional español ha acogido en ocasiones de manera tácita la tesis de la eficacia directa de los Derechos Fundamentales en las relaciones entre particulares, en tanto en otras oportunidades ha defendido la eficacia indirecta; pueden verse, entre otras, las SSTC 18/1984, de 7 de febrero; 47/1985, de 19 de abril, o 170/1987, de 30 octubre; en fin, de acuerdo con la STC 177/1988, de 10 de octubre: "el art. 53.1 del Texto constitucional tan sólo establece de manera expresa que los derechos fundamentales vinculan a los poderes públicos, pero ello no implica una exclusión absoluta de otros posibles destinatarios, dado que, como señala la STC 18/1984 (fundamento jurídico 6º), 'en un Estado social de Derecho no puede sostenerse con carácter general que el titular de tales derechos no lo sea en la vida social'. De aquí que este Tribunal haya reconocido que los actos privados puedan lesionar los derechos fundamentales y que en estos supuestos los interesados pueden acceder a la vía de amparo si no obtienen la debida protección de los Jueces y Tribunales a los que el ordenamiento encomienda la tutela general de los mismos. Las relaciones entre particulares, si bien con ciertas matizaciones, no quedan, pues, excluidas del ámbito de aplicación del principio de igualdad, y la autonomía de las partes ha de respetar tanto el principio constitucional de no discriminación como aquellas reglas, de rango constitucional u ordinario, de las que se derive la necesidad de igualdad de trato. No cabe olvidar que el Art. 1.1 C. E. propugna entre los valores superiores del ordenamiento jurídico la igualdad, y que el 9.2 encomienda a todos los poderes públicos promover las condiciones para que la igualdad del individuo y de los grupos en que se integra sean reales y efectivas".

Por su parte, la Ley Orgánica del Tribunal Constitucional (LOTC) no contiene referencia alguna al Recurso de amparo frente a actos de los particulares. No obstante, el Tribunal Constitucional español ha seguido en buena medida la construcción alemana del denominado amparo indirecto contra los actos de los particulares cuando ha tenido necesidad de echar mano de la misma para responder a la cuestión sustantiva, a base de imputar la vulneración del Derecho Fundamental al órgano judicial que no otorgó en la instancia la protección debida (STC 55/1983, de 22 de junio).
} 
prevalecer y tener eficacia en las relaciones horizontales (recíprocas) de los ciudadanos entre sí.

En tercer término, la plasmación más reciente (aunque de mayor envergadura, tanto desde el punto de vista cualitativo como del sistemático) de la dimensión jurídico-objetiva, viene constituida por la teoría de las obligaciones o deberes de protección general a cargo del Estado, que se revela en el concepto central o la consecuencia fundamental -aunque sólo fuera por lo obligado una vez más de hacer de la necesidad virtud-, y ante el carácter meramente hipotético de las tesis abstencionistas en orden a alcanzar una igual libertad-autonomía sin la intervención del Estado. Deber de protección eminentemente activo de los Derechos Fundamentales dirigido en primer lugar al legislador, sin que necesariamente se le obligue en todo caso a llevar a cabo una habilitación subjetiva y aunque evidentemente no se la excluya, pero obligación que informa asimismo la interpretación, ejecución y aplicación de las normas. En las coordenadas apuntadas, los Derechos Fundamentales no garantizan exclusivamente un espacio de libertad rechazando intromisiones concretas o un derecho general de no intervención en el ámbito protegido, sino que incorporan, además, un orden de valores objetivo, considerado a modo de decisión material y fundamental de Derecho constitucional para todos los sectores del ordenamiento.

En este sentido, si los Derechos Fundamentales como orden de valores persiguen adquirir notoriedad y eficacia concreta en el ordenamiento jurídico, penetrar en todo él, resulta lógica su conversión en directrices, guía y criterio para todas las leyes que se refieren al ámbito vital amparado por el Derecho Fundamental en cuestión. Y en este ámbito de libertad constituida ${ }^{16}$, alcanzan una importancia positiva, activadora o promocional, por cuanto incluyen, al mismo tiempo, la obligación para los poderes públicos en el plexo de sus actividades de cooperar a la realización efectiva del haz de facultades integrantes de su contenido. Así, el Estado social viene obligado a proporcionar recursos personales, materiales y financieros e institucionales, en orden a la realización de los Derechos. El efecto de los Derechos Fundamentales no se refiere, en este caso, a una omisión o abstención por parte del Estado, sino inversamente al desarrollo de una acción positiva. En definitiva, en esta obligación de protección-Schutzpflicht- se desarrolla en buena parte el contenido objetivo del Derecho Fundamental, y se estructura conforme a una relación triangular: el Estado protege activamente el comportamiento de los individuos en el ejercicio de un Derecho Fundamental, sea contra los perjuicios que puedan causarles la acción o la omisión de los poderes públicos, sea frente a los ocasionados por

${ }^{16}$ Al efecto, LüBBE-WolfF, Gertrude, Grundrechte als Eingriffabwehrrechte, Nomos, Baden-Baden, 1988. 
otros ciudadanos o grupos sociales que pretenden beneficiarse de la intromisión ilegítima o meramente de la debilidad de los primeros.

No es ahora la alternativa ideal, pues, la del bourgeois despolitizado y defensor del statu quo social que vela por su propio interés ante los tribunales, sino la del ciudadano activo que se integra en el Estado, y precisamente con la ayuda de éste. Y semejante comprensión del Estado como una superior asociación pluralista de derechos (que había tenido eximios antecedentes en H. Preuss, o en H. Laski), significa un acusado enriquecimiento de aquél, pero implica también el contrapunto pluralista y público -die Öffentlichkeit- a la vieja unidad del Estado plegado sobre sí mismo y deliberadamente situado al margen de todo impulso transformador. Sin olvidar que la trilogía Estado, grupos sociales y personas individuales, se sobrentienden como interpenetrados y libres; corrigiendo de este modo la tendencia natural de todo intento de rebasarse los unos a los otros. Actualmente, sostiene D. Grimm, apenas se discute que los ámbitos de autodeterminación no intervenidos por el Estado y garantizados por los Derechos Fundamentales, únicamente lograrán su objetivo de libertad-autonomía si se les protege igualmente contra el poder social y cuentan con fundamentos materiales suficientes que permitan al individuo hacer un uso real de su libertad. Carece de fundamento, recuerda el autor precitado, la afirmación de E. Forsthoff en el sentido de que la Constitución no resulta idónea para cumplir este tipo de funciones ${ }^{17}$, pues no sólo las restricciones formales de actuación y las normas procedimentales, sino también los preceptos de configuración material basados en el consenso de la sociedad pueden desarrollar fuerza normativa, pese a no servir de manera directa para la subsunción judicial en un conflicto jurídico.

El legislador y las instancias aplicadoras del Derecho, en particular los órganos judiciales, deberán hacerse eco de los Derechos Fundamentales en la producción, exégesis y empleo de los textos lingüísticos mediante los que se determinan los programas normativos de las normas jurídicas iusfundamentales ${ }^{18}$. Y en tanto cuestión constitucional, señala la literatura jurídica alemana, compete al control del Bundesverfassungsgericht (Tribunal Constitucional Federal) enjuiciar si tal postulado ha sido o no tenido suficientemente en cuenta; aspectos sobre los que volveremos. En definitiva, concluirá $K$. Hesse, a partir de

\footnotetext{
${ }^{17}$ Como se sabe, desde su concepción formalista y positivista del Estado de Derecho, concluía Ernst Forsthoff que la Constitución sólo era concebible como Constitución del Estado de Derecho, y que no se abría a otras finalidades, sobre todo a las del Estado social. Sin embargo, su concepción acerca del Estado de Derecho no arranca del derecho positivo contenido en la Ley Fundamental ni del estado de la discusión científica, sino de la teoría constitucional del Carl Schmitt decisionista, ForsTHOFf, Ernst, "Die Umbildung des Verfassungsgesetzes", en BARIon, Hans; Forsthoff, Ernst; Weber, Werner (Comps.), Festschrift für Carl Schmitt 70 Geburtstag, Duncker \& Humblot, Berlín, 1959, pp. 35 y ss.

${ }^{18}$ Para esta concepción de la norma jurídica remitimos a MülLer, Friedrich; VILLACORTA MANCEBo, Luis Quintín, Postpositivismo, TGD, Santander, 2008.
} 
las consecuencias extraídas del desarrollo de la teoría del doble carácter de los Derechos Fundamentales, se evidencia no sólo la conveniencia sino la obligatoriedad de concebir al Derecho Constitucional como Derecho Fundamental, y su comprensión asimismo en cuanto Derecho que pone un fundamento universal de las personas individuales, de las sociedades y de la organización del Estado, debajo de un Derecho de la Comunidad Internacional (incluso, claro está, de la Unión Europea), que no es solamente Comunidad de Estados en los términos pretendidos por la achatada concepción positivista clásica del Derecho Internacional. De otra parte, quedan así al descubierto las insuficiencias de una teoría y un modelo de la Ciencia del Derecho Constitucional dominados por el postulado de su entendimiento en cuanto Derecho del Estado y como Derecho Público General; la Constitución, concluirá reiteradamente en esta línea el Tribunal Constitucional español, se constituye de este modo en la base general de todo el ordenamiento jurídico, tanto del Derecho público como del Derecho privado.

A su vez, sigue siendo válida la idea de que la interpretación de los Derechos Fundamentales debe continuamente esforzarse a objeto de evitar el distanciamiento de su significado primario y específico, a fin de no caer en una improductiva autonomización propia de un complejo de normas objetivas, en cuyo caso el sentido también originario y constante de los Derechos pasaría a segunda línea en cuanto parcialmente ahogado por una especie de comunitarismo coactivo. Porque es en la vertiente de derechos subjetivos de defensa donde los Derechos Fundamentales despliegan inmediata y totalmente su fuerza vinculante $(H$. Nogueira); si bien, en realidad, existe y debe preservarse la concomitante e indisoluble conexión entre ambas vertientes. Ahora bien, esta transformación estructural de los Derechos Fundamentales y del ordenamiento jurídico en su conjunto, ha terminado por difuminar en toda su extensión la línea separadora entre el Derecho constitucional (dotado de primacía) y el Derecho ordinario. Debido a su fuerza expansiva, señalan $R$. Wahl y J. Wieland, en último término "todo está influido, irradiado e informado por los Derechos Fundamentales (...) lo que ha llevado a que respecto de una resolución contraria a Derecho (sea judicial o administrativa) no quepa ya distinguir, desde un punto de vista material, si la antijuricidad es debida a la infracción únicamente del Derecho ordinario o a la vulneración del contenido en Derecho Fundamental (por irradiación) de un determinado precepto". E idea semejante ha llevado a afirmar al Tribunal Constitucional español, en su sentencia 50/1984, de 5 de abril, que la distinción "entre la jurisdicción constitucional y la ordinaria no puede ser establecida, como a veces se hace, refiriendo la primera al plano de la constitucionalidad y la jurisdicción ordinaria al de la simple legalidad, pues la unidad del ordenamiento y la supremacía de la Constitución no toleran la consideración de ambos planos como si fueran distintos e incomunicables". 
En fin, desde nuestro entorno geográfico y económico-político, si se observa la Carta europea de Derechos Humanos, puede verificarse que la expansión de los derechos forma parte decidida del futuro europeo, y lo mismo cabe decir de la tendencia hacia su universalización constatable en otras latitudes, muy singularmente en el constitucionalismo latinoamericano.

\section{El doble carácter de los Derechos Fundamentales EN EL ORDENAMIENTO JURÍDICO ESPAÑOL}

Tocante al ordenamiento jurídico español, el propio texto de la Constitución expresa en el importante Art. de la 10.1 que los Derechos Fundamentales conforman "el fundamento del orden jurídico y de la paz social". Por su parte, el Tribunal Constitucional, desde la consideración de la dignidad humana (Art. 10 de la CE) -junto al derecho a la vida (Art. 15 de la CE)-, como el "prius lógico y ontológico para la existencia y especificación de los demás derechos"19, y claramente influenciado una vez más por la jurisprudencia constitucional alemana sobre la materia, ha reconocido, asimismo, a partir de la sentencia 25/1981, la doble vertiente de los Derechos Fundamentales de forma indubitada. En este sentido, declarará: "Ios Derechos fundamentales y las libertades públicas (...) constituyen el fundamento mismo del orden político-jurídico del Estado en su conjunto (...) ello resulta lógicamente del doble carácter que tienen los Derechos fundamentales".

Además, el Tribunal Constitucional español también contrapone a esta vertiente de los Derechos Fundamentales como derechos subjetivos exigibles por sus titulares frente a los poderes públicos, las obligaciones de protección fruto de la importancia objetiva de los mismos, al afirmar con toda claridad: "En primer lugar, los Derechos fundamentales son derechos de los individuos no sólo en cuanto derechos de los ciudadanos en sentido estricto, sino en cuanto garantizan un status jurídico o la libertad en un ámbito de la existencia", pero, de inmediato, se refiere a su vertiente objetiva, ya que asimismo estima han de considerarse normas objetivas de un sistema de valores. Esto es, considera que "al propio tiempo, son elementos esenciales de un ordenamiento objetivo de la comunidad nacional, en cuanto ésta se configura como marco de una convivencia humana justa y pacífica, plasmada históricamente en el Estado de Derecho y, más tarde, en el Estado social de Derecho o el Estado social y democrático de Derecho, según la fórmula de nuestra Constitución (Art. 1.1)". Doble naturaleza de los Derechos Fundamentales, recuerda la sentencia, desarrollada doctrinalmente, y recogida de forma expresa por el Art. 10.1 de la Constitución, a tenor del cual "la dignidad de la persona, los derechos invio-

${ }^{19}$ STC 53/1985, de 11 de abril. 
lables que le son inherentes, el libre desarrollo de la personalidad, el respeto a la ley y a los derechos de los demás son fundamentos del orden político y de la paz social' (...). En el segundo aspecto, en cuanto elemento fundamental de un ordenamiento objetivo, los Derechos fundamentales dan sus contenidos básicos a dicho ordenamiento, en nuestro caso al del Estado social y democrático de Derecho, y atañen al conjunto estatal (...) fundan un status jurídico-constitucional unitario para todos los españoles y son decisivos en igual medida para la configuración del orden democrático (...) son elemento unificador (...) son así un patrimonio común de los ciudadanos individual y colectivamente, constitutivos del ordenamiento jurídico cuya vigencia a todos atañe por igual. Establecen una vinculación directa entre los individuos y el Estado y actúan como fundamento de la unidad política".

Así las cosas, el efecto irradiación derivado de la naturaleza de normas objetivas supremas propia de los Derechos Fundamentales y la consiguiente ubicuidad de los mismos en sistema jurídico, se dibuja, entre otras, en la STC 21/1981, de 15 de junio: "los Derechos fundamentales responden a un sistema de valores y principios de alcance universal que subyacen a la Declaración Universal y a los diversos convenios internacionales sobre Derechos Humanos, ratificados por España, y que, asumidos como decisión constitucional básica, han de informar todo nuestro ordenamiento jurídico". Y de forma si cabe aún más nítida, la doble dimensión de los Derechos Fundamentales vuelve a reflejarse en otra importante sentencia del Alto Tribunal español, nos referimos a la STC 53/1985, de 11 de abril: "Es pertinente hacer, con carácter previo, algunas referencias al ámbito, significación y función de los Derechos fundamentales en el constitucionalismo de nuestro tiempo inspirado en el Estado social de Derecho. En este sentido, la doctrina ha puesto de manifiesto -en coherencia con los contenidos y estructuras de los ordenamientos positivos- que los Derechos fundamentales no incluyen solamente derechos subjetivos de defensa de los individuos frente al Estado, y garantías institucionales, sino también deberes positivos por parte de éste (vide al respecto Arts. 9.2; 17.4; 18.1 y $4 ; 20.3 ; 27$ de la Constitución). Pero, además, los Derechos fundamentales se erigen en los componentes estructurales básicos, tanto del conjunto del orden jurídico objetivo como de cada una de las ramas que lo integran, en razón de que son la expresión jurídica de un sistema de valores que, por decisión del constituyente, ha de informar el conjunto de la organización jurídica y política; son, en fin, como dice el Art. 10 de la Constitución, el 'fundamento del orden jurídico y de la paz social'". De la significación y finalidades de los Derechos Fundamentales dentro del orden constitucional, deduce el Tribunal Constitucional español que la garantía de su vigencia no se puede limitar a la mera "posibilidad del ejercicio de pretensiones por parte de los individuos, sino que ha de ser asumida también por el Estado". En consecuencia, a partir de la obligación de sometimiento de 
todos los poderes a la Constitución es posible estimar "la obligación negativa del Estado de no lesionar la esfera individual o institucional protegida por los Derechos fundamentales", pero asimismo, "la obligación positiva de contribuir a la efectividad de tales Derechos, y de los valores que representan, aun cuando no exista una pretensión subjetiva por parte del ciudadano. Ello obliga especialmente al legislador, quien recibe de los derechos fundamentales 'los impulsos y líneas directivas', obligación que adquiere especial relevancia allí donde un derecho o valor fundamental quedaría vacío de no establecerse los supuestos para su defensa". Todo lo cual, dista de una vuelta a la interpretación liberal, que obligaría a la restitución en favor del legislador del derecho a perseguir cualesquiera fines de la colectividad hasta el límite del contenido esencial de los Derechos Fundamentales.

\section{La esencial garantía de los Derechos Fundamentales POR MEDIO DE LA JURISDICCIÓN CONSTITUCIONAL}

Toda vez que los Derechos Fundamentales tienen la considerada eficacia normativa inmediata, resultando así la Constitución la norma directamente aplicable a casos concretos en los que está en juego un Derecho fundamental, y en atención a ése su reconocido carácter esencial para la constitución y pervivencia de la comunidad política, su vigencia, respeto y garantía, constituye una cuestión esencial de la legitimidad del Estado, porque la soberanía del pueblo se orienta al logro de la libertad real-efectiva (W. Leisner). Por ello, los Derechos Fundamentales se protegen por su importancia, si bien, tal importancia no deriva obviamente de su protección, al menos no exclusiva y primordialmente. Encontramos ahí la justificación de que buena parte de los mismos reciban una protección jurisdiccional privilegiada (tutela a través del Recurso de Amparo constitucional) por parte de órganos constitucionales independientes que ocupan una posición y desarrollan una función central en la estructura del Estado constitucional moderno, atendida sea su condición de intérpretes supremos y guardianes de la Constitución. Dicho de otro modo, protección especial otorgada a aquellos que tienen en el ordenamiento español un plus de fundamentalidad, vale decir, los comprendidos en el Art. 14 de la CE, la Sección $1^{\text {a }}$ del capítulo segundo, del Título I de la CE, esto es, en los Arts. 15 a 29 (aunque en relación con algunos de los mismos se suscite perplejidad por comparación a los incluidos en la Sección $2^{a}$ del propio capítulo segundo), y la objeción de conciencia al servicio militar (Art. 30.2 de la CE). En esta línea, el Tribunal Constitucional español declararía en su primera sentencia que la finalidad del Recurso de Amparo constitucional "es la protección, en sede constitucional, de los derechos y libertades (....) cuando las vías ordinarias de protección han resultado insatisfactorias", designio, prosigue la sentencia, proclamado en el Art. 53.2 de la CE, pero junto a la que "aparece también el de la defensa objetiva 
de la Constitución, sirviendo de este modo la acción de amparo a un fin que trasciende de lo singular" 20.

Más tarde, dirá el Tribunal Constitucional español que el Recurso de Amparo "no es una instancia más, entre las que se encadenan en el iter procesal de una determinada pretensión. Por su misma función, se trata de un recurso extraordinario, encaminado a la tutela de los Derechos fundamentales y Libertades públicas (Arts. 53. 2 de la CE y 41 de la LOTC), que tiene autonomía respecto de la actuación procesal desarrollada en la instancia. Por esta razón, por la específica naturaleza del recurso y de las pretensiones ejercitadas en él"21. En fin, la STC 135/2004, de 5 de agosto, declarará que el Recurso constitucional de Amparo ofrece "el remedio último frente a cualquier vulneración de los derechos y libertades enunciados por el Art. 53.2 de la Constitución, cometida por cualquier poder público". Y cabe recordar con carácter general al efecto, que los tribunales constitucionales disponen de una legitimidad democrática de origen (por el modo de designación de sus miembros) más intensa que la de los jueces y tribunales ordinarios. Aspecto este último determinante (aunque ahora no podamos detenernos), habida cuenta de los elementos políticos que alberga inevitablemente toda interpretación de normas constitucionales abiertas ( $K$. Hesse), y considerando que a la mayor legitimidad democrática de la norma a enjuiciar corresponde una mayor legitimidad democrática de origen del órgano encargado de su enjuiciamiento $(E$. Cheli). Porque el papel extraordinario desarrollado por la jurisdicción constitucional, su autoridad, deriva de este lugar singular que el Tribunal Constitucional ocupa en el orden constitucional, lo que le permite desarrollar su influencia en la democracia conforme al postulado del Estado constitucional de Derecho, cuyo contenido material y peculiaridad no serían concebibles actualmente sin la aportación de la jurisprudencia constitucional $^{22}$. En atención al antedicho su lugar constitucional privilegiado, a diferencia de los tribunales ordinarios cuyas decisiones producen exclusivamente normas individuales, los Tribunales constitucionales deciden a través de decisiones de alcance general. Cuando el Tribunal Constitucional anula una norma general produce un contrarius actus, lo que le convertía ya a juicio de H. Kelsen en legislador negativo, aun cuando hoy se haya dado la vuelta a la

\footnotetext{
${ }^{20}$ STC 1/1981, de 26 de enero, y 69/1997, de 8 de abril, entre otras.

${ }^{21}$ STC 143/1994, de 9 de mayo.

${ }^{22}$ Tal como recuerdan Rainer Wahl y Frank Rottmann, ya con el constitucionalismo democrático de la República de Weimar se generó la conciencia acerca de que el significado de una Constitución se diferenciaba cualitativamente en virtud de la existencia o inexistencia de una jurisdicción constitucional, WAHL, Rainer; ROTTMANN, Frank, "Die Bedeutung der Verfassung und der Verfassungsgerichtsbarkeit in der Bundesrepublik - ein Vergleich zum 19. Jahrhundert und zu Weimar", en Werner Conze; M. Rainer Lepsius (Edits.), Sozialgeschichte der Bundesrepublik Deutschland: Beiträge zum Kontinuitätsproblem, Stuttgart, Klett-Cotta, 1983, p. 339.
} 
tesis, y si bien en el propio autor citado el Tribunal Constitucional termine por configurarse como legislador negativo y positivo al mismo tiempo. Recuerda así nuestra LOTC, que en cuanto intérprete supremo (Art. 1.1), el Tribunal está exclusivamente sometido a la Constitución cuya primacía garantiza (Art. 27.1) y a la propia Ley Orgánica precitada, evitando con ello que la política constitucional desarrollada por el Alto Tribunal vulnere el carácter normativo de la Constitución y el principio democrático. También cuando se trata de Derechos Fundamentales, en el juicio de constitucionalidad funda el Tribunal su decisión en los propios preceptos constitucionales, o al menos a partir de los textos de los mismos, y contribuye una y otra vez a la "conformación jurisprudencial" dinámica de aquéllos.

En consecuencia, no es desdeñable la idea del Recurso de Amparo constitucional como control de la ley y garantía de los Derechos Fundamentales allí donde no alcanza la función restauradora o reparadora del Poder Judicial ordinario. Porque, además del interés propio y subjetivo, del interés legítimo que resulta obligado invocar para interponer el Recurso de Amparo constitucional (tal como dispone el Art. 162.1.b de la CE), a la postre, está siempre presente en un recurso de este carácter la defensa de un interés abstracto u objetivo, a consecuencia del considerado doble carácter de los Derechos, esto es, de protección del orden jurídico-objetivo de valores establecidos por la Constitución a través del sistema de Derechos Fundamentales. También en vía de amparo, por lo tanto, el Tribunal Constitucional opera como supremo intérprete constitucional. De este modo, al objeto de apreciar si existe una efectiva vulneración de los Derechos Fundamentales, puede ser ineludible abordar la interpretación llevada a cabo por los órganos judiciales de la normativa infraconstitucional que desarrolla o incide en el Derecho Fundamental afectado, al objeto de proceder, en su caso, a la revisión de la decisión judicial. Al mismo tiempo, a partir de la comparación entre los sistemas alemán y español, es considerado decisivo por la doctrina científica española el hecho de que en ambos ordenamientos la impugnación de decisiones judiciales no haya de fundarse necesariamente en un defecto de constitucionalidad de la ley aplicada, ya que resulta posible no dirigir reproche alguno contra la legitimidad constitucional de la Ley aplicable e imputar, sin embargo, al órgano judicial la lesión del Derecho fundamental por haber aplicado incorrectamente la norma, o por aplicar otra no pertinente al caso. Debido a esta razón, el Recurso de Amparo constitucional se ha convertido en España en un eficaz medio de control de los actos del juez ordinario, dado que el Tribunal Constitucional no controla únicamente las leyes y otras normas y actos de los poderes públicos, sino también la interpretación previamente realizada por los órganos judiciales. Por consiguiente, dejando ahora aparcada la cuestión de si la función básica del Tribunal Constitucional es o no la de una concreta reacción frente a singulares vulneraciones de Derechos 
Fundamentales, se puede afirmar que el control aludido opera sobre el modo en que los jueces y tribunales ordinarios aplican los preceptos constitucionales reguladores de los Derechos Fundamentales. Cuando el Tribunal Constitucional decide en un Recurso de Amparo, preserva o restablece a un ciudadano en el Derecho Fundamental que le ha sido vulnerado, pero realiza, además, una función de alcance general, al determinar la forma conforme a la cual los jueces y tribunales ordinarios han de operar en este tipo de supuestos. De esta forma, a través del Recurso de Amparo, el Tribunal Constitucional puede llevar a término un control efectivo sobre el modo a través del cual los tribunales ordinarios aplican el sistema de fuentes establecido, e imponer la observancia de la jurisprudencia constitucional como única vía posible al objeto de lograr una interpretación uniforme de la Constitución.

Así las cosas, se ha considerado que la institucionalización de los tribunales constitucionales obedeció a la confianza que se tuvo en que estos específicos y cualitativamente exclusivos tribunales iban a proteger de modo especial a la Constitución y a los Derechos Fundamentales en particular; unos derechos que gozan del más fuerte respaldo social. En consecuencia, la jurisdicción constitucional está obligada a vivir de la confianza ciudadana depositada en ella como institución destinada a perfeccionar la vigencia del Estado de Derecho en el que se ha constituido la nación española en virtud de una decisión fundamental expresada en el preámbulo y en el Art. 1.1 de la Constitución, confianza que ha de ganarse luego a través de su actividad decisoria y que contrasta con la desconfianza que acompaña a la actividad estrictamente política, contribuyendo a fortalecer, en lo que ahora nos toca, la materialidad individual y colectiva de los Derechos Fundamentales. Es preciso tener en cuenta que bajo formas jurisdiccionales, con carácter general, el control llevado a cabo por el Tribunal Constitucional tiene naturaleza política; algo obvio, por demás, si partimos de la idea subyacente a la jurisdicción constitucional, esto es, la de someter la acción política al control de un Tribunal ${ }^{23}$.

En efecto, el Tribunal Constitucional es también una instancia política de poder que participa en la dirección de la política constitucional del Estado, aunque no fuera más que por su contribución al desarrollo y evolución del Derecho Constitucional, un Derecho al que interpreta y aplica con carácter supremo y un Derecho de claro contenido político que establece los principios configuradores de la unidad política, pues normativiza los valores en que ésta se sustenta (E. Álvarez Conde). No obstante, sin remitirnos a autores por así decir más clásicos, autores actuales, vamos a decir "experimentados", que parten

\footnotetext{
${ }^{23}$ Ahora bien, tal como ha precisado el mismo Konrad Hesse, la jurisdicción constitucional nunca puede resolver crisis políticas profundas, pues su eficacia se limita a regular el funcionamiento regular, cotidiano, del sistema democrático, en los casos de conflictos habituales y previsibles.
} 
en ocasiones de precomprensiones distintas, cual es el caso, entre otros, de $D$. Grimm, P. Badura, J. Isensee o F. Müller, alertan acerca de la imposibilidad de una juridificación total de la política, y más dada su intensidad actual. De otra parte, ello tampoco es deseable, por constituir un peligro del que se debe huir en no menor medida que del peligro opuesto por así decirlo, esto es, el de una politización total del ordenamiento. De manera particular, también es cierto, la plena justiciabilidad de los Derechos Fundamentales se ha perfilado en ocasiones como un ideal, pero tampoco consideramos que tal ideal sea susceptible de ser cumplido en términos absolutos.

Ciertamente, el Derecho constitucional es un Derecho radicalmente distinto de todos los demás, a causa de la especificidad del objeto sobre el cual incide y, debido a ello, por su pretensión aludida de conformar jurídicamente la política, esto es, someterla a metas y fines definidos jurídicamente (D. Grimm), así como por la particularidad de los métodos que conforman sus instrumentos de trabajo. Y, cuanto menos jurídicamente se halle vinculada la política, mayor será la libertad de quien decide, en tanto, por el contrario, cuanto más fuerte sea la vinculación del órgano encargado de decidir, tanto menor será el espacio para el ejercicio de la política, entendiendo por ésta la actividad de elegir libremente por parte de los poderes constituidos en el marco de la legalidad ${ }^{24}$. Las constituciones normativas no se basan en la idea de que cada decisión adoptada por los poderes públicos deba remitirse a una autorización del Derecho constitucional, aunque sí se les impone importantes restricciones tanto formales como materiales. En consecuencia, la perspectiva metodológica propia del Derecho constitucional reside, entre otros aspectos, en lograr el equilibrio entre los dos polos antes considerados, en alcanzar la equidistancia entre estos dos extremos opuestos que pueden ocasionar su negación (J. Isensee). De este modo, como subraya el autor precitado, encontrar y perfilar semejante perspectiva metodológica no es tarea fácil, por lo que las respuestas a la pregunta quid juris, habitualmente son más arduas de obtener en las cuestiones jurídico-constitucionales comparadas con las dificultades que la misma plantea a otras ramas del Derecho. En tal contexto, de nuevo es necesario estar de acuerdo con F. Müller, acerca de la alerta permanente derivada de la necesidad no sólo de renovar continuamente la dogmática de los Derechos Fundamentales, sino asimismo, la política constitucional de los Derechos Fundamentales, pues existen dimensiones iusfundamentales que no pueden hacerse prevalecer ante los tribunales o tan solo pueden lograrse de forma muy restringida, mientras proseguirán apareciendo otras justiciables y no justiciables apenas hoy insospechadas. Pero ahora, y al mismo tiempo, si

${ }^{24}$ Badura, Peter, "Die Verfassung im Ganzen der Rectsordung und die Verfassngskonkretisierung durch Gesetze", en IsenseE, Josef; KIRCHHOF, Paul (Comps.), Handbuch des Staatsrechts der Bundesrepublik Deutschland, Bd. VII. Heidelberg, C.H. Müller, 1992, pp. 185 y ss. 
nos ceñimos a la tarea de los juristas, también la dogmática de los Derechos Fundamentales, por así decirlo "no justiciable", tiene una importancia general y específica de primera magnitud, siendo éste un ámbito al que la literatura jurídica española apenas se ha aplicado. Y en fin, tocante a la renovación de la política constitucional de los Derechos Fundamentales, los juristas no sólo deben, están obligados a contribuir, a intervenir de manera decidida, responsable e imaginativa: la función del Derecho constitucional no entendemos sea la de atender únicamente a la conservación del modelo social, sino la de contribuir a su transformación, aunque el impulso fundamental corresponda efectivamente a la política. Por lo tanto, no debemos subestimar la fecundidad de la teoría constitucional no justiciable de los Derechos Fundamentales, tan importante cualitativamente como la teoría constitucional justiciable; lo cual es sensiblemente distinto, naturalmente, del importante recelo que, desde planteamientos fuertemente neoliberales y relativistas, plantea por ejemplo J. Waldron, al cuestionar decididamente la función del Poder Judicial en la protección de los Derechos Fundamentales ${ }^{25}$. Los sistemas democráticos sin Constitución justiciable a través de una jurisdicción constitucional plena (caso de Francia) pueden constituir un espejo al respecto, y la realidad demuestra que el pleno ejercicio de los Derechos Fundamentales no depende exclusivamente del perfeccionamiento del sistema de garantías jurídicas protectoras.

Ahora bien, volviendo sobre el carácter propio de los tribunales constitucionales, no debe extrañarnos, afirma la doctrina científica alemana, que ya resulte imposible su descripción con claridad (tanto hoy como en la retrospectiva de los años cincuenta del pasado siglo) con el concepto de tribunales, pues si se les compara con otros tribunales ordinarios sólo se les asemejan. El Tribunal Constitucional Federal se Ilama tribunal (utilizando el concepto sin prejuicio alguno), si bien, se dirá, únicamente se parece a un tribunal (Ch. Gusy). Las diferencias respecto a otros tribunales integrantes de la jurisdicción ordinaria conciernen fundamentalmente a la forma de su participación extraprocesal en los acontecimientos políticos, y desde luego, también a su forma de aplicar justicia, incluso a veces por la vía de asesoramiento. Las diferencias alcanzan incluso a aspectos externos, la representación del Tribunal, su labor de relaciones públicas, sus comunicados de prensa, todo lo cual ha de desarrollarse por medio de una habilidad notable, buscando la aceptación: sobre todo, si mediante las resoluciones pretende provocar un "cambio de concienciación en la política y en el público" (H. Schulze-Fielitz). Simultáneamente, en lógica consecuencia, es uno de los garantes de la estabilidad democrática, porque el pueblo, de quien procede la legitimidad democrática que exige la Constitución (principio democrático que se extiende, obviamente, a cualquier modo de ejercer el poder en el Estado consti-

${ }^{25}$ Véase, WALDron, Jeremy, Derecho y desacuerdos, Marcial Pons, Madrid, 2005. 
tucional), no está presente únicamente el día de las elecciones como magnitud unitaria, sino pluralmente en el proceso de interpretación constitucional, ya sea como partido, grupo de interés e incluso como ciudadano.

A tal efecto, la propia doctrina científica alemana recuerda con frecuencia la fórmula ritual: "en nombre del pueblo", con la que inicia el Bundesverfassungsgericht sus sentencias, así como la "función de reserva" propia de la jurisdicción constitucional, y aun sin llegar al extremo de interpretar que los jueces constitucionales sean meros portavoces del titular de la soberanía, considera que el derecho judicial emanado del Recurso de Amparo permite concretar la Constitución así como ayudar a que ésta eche raíces. Porque, hace ya tiempo que la Constitución, concebida como proceso público, ha dejado de ser únicamente un asunto del Estado y de su Derecho público, en cuanto su alcance (sobre todo en lo que concierne a los Derechos Fundamentales) Ilega a ámbitos descritos tradicionalmente como propios de la esfera de la Sociedad, hasta hacer aparecer así a la Constitución como el orden fundamental normativo de toda la colectividad. Por las aludidas procedencia de sus miembros y características de su función, los tribunales constitucionales se proyectan como órganos idóneos al objeto de mantener la vigencia efectiva de los valores constitucionales (G.F. Mendes), cuya naturaleza inherente estriba en no abrirse a un pleno esclarecimiento, pues están siempre rodeados de niebla; sistema de valores, de otra parte, de alcance universal, pues al margen de las peculiaridades propias del ámbito nacional, sobresale con creces el rasgo de la homogeneidad de aquéllos en el contexto de las democracias pluralistas. Sin embargo, el presupuesto para dar entrada y justificar el rol importante asumido por los tribunales constitucionales en la defensa de los Derechos Fundamentales a través del control de constitucionalidad, no estriba, como sostiene J. Waldron, en el hecho de considerar que los procedimientos democráticos mayoritarios puedan producir resultados decididamente injustos e incluso tiránicos. Éste sería un falso presupuesto, con carácter general, puesto que, si bien discutibles en el contexto de cualquier sociedad democrática, las decisiones del legislador democrático no presentan ni siquiera excepcionalmente ese nivel de degradación. El control de constitucionalidad no supone la suplantación de la voluntad de otro órgano, tan sólo determina si el órgano controlado ha rebasado los límites constitucionales. Y mucho menos justificado está aún cuestionar la legitimidad de los jueces constitucionales por el hecho de no haber sido directamente elegidos por los ciudadanos; esto supone desconocer en muy amplia medida el significado real del principio democrático ${ }^{26}$. Planteamientos de este tipo incurren en un error

${ }^{26}$ La institucionalización del Tribunal Constitucional, por tanto, es la consecuencia lógica de la culminación del Estado constitucional; es la forma de expresar que se concede prioridad en último extremo y en caso de conflicto al Derecho -constitucional-sobre la política. Vincular la política a la ratio de 
fundamental, porque la legitimación de la jurisdicción constitucional no se puede determinar en función de la cercanía al pueblo manifestada por el acto de votar, sino que reside más bien en la lógica del Estado constitucional. Esto es, el Estado constitucional ha legitimado institucionalmente la jurisdicción constitucional, habiéndola dotado ya por el poder constituyente de la legitimación que le es propia. Y de esta legitimación forma parte que el Tribunal Constitucional cumpla su función de control sólo mediante un procedimiento específico de creación jurídica formalmente ordenado. Por lo tanto, sería un planteamiento equivocado buscar la legitimación del Tribunal Constitucional en el acto de votar o en la "cercanía del pueblo" sugerida por al acto mismo de la votación. La legitimación jurídico-constitucional emana institucionalmente de la propia Constitución que ha decidido colocar la legitimidad institucional del Tribunal como equivalente y al lado de la otorgada por las elecciones. Y esta legitimación institucional se complementa y desarrolla calificando la función del Tribunal Constitucional de "jurisdicción" -Art. 161.1 CE-, la cual, a su vez, se distingue de los procesos de decisión de las instancias políticas tanto por el status de los magistrados que resuelven, en particular por su independencia, como por la forma de creación jurídica. Por tanto, el reproche que pueda hacer al legislador, de haber sobrepasado los límites competenciales, no es ni mucho menos infamante, y lo es menos en determinadas materias, como ha reconocido E.G. Mahrenholz, para quien de forma más concreta la jurisprudencia constitucional en materia de Derechos Fundamentales es siempre una "labor milimétrica" a realizar, plena de dudas respecto de si una opinión diferente no tiene idéntica justificación ${ }^{27}$.

la Constitución como norma fundamental del ordenamiento forma parte de la esencia y singularidad del Estado constitucional, pero para ello es necesario que exista un órgano capaz de actualizar esa vinculación en el ámbito de un procedimiento de concretización/aplicación jurídica. Esta constatación da lugar a tensiones e incluso problemas estructurales, constitutivos de un ámbito amplio que puede contemplarse bajo numerosos aspectos y en los que no es nuestro propósito entrar en estos momentos. Sin embargo, el pretendido constitucionalismo popular, caracterizado por la desconfianza frente a lo que denominan eufemísticamente elitismo, cuestiona la que entienden veneración de los órganos jurisdiccionales. En tal dirección autores como, ente otros, Jeremy Waldron, Mark Tushnet o Larry Kramer sostienen una postura radical, deslegitimando todo tipo de control constitucional por parte de los jueces, ante la insensatez que consideran la encomienda de resolver por medio del Poder Judicial las divisiones de la sociedad adoptadas por regla mayoritaria a través del Poder Legislativo en cuanto poder en inmediatez con la ciudadanía en un sistema democrático. El planteamiento, por demás, recuerda a la denominada dificultad contramayoritaria teorizada unas décadas antes por Alexander Bickel: "cuando la Suprema Corte declara inconstitucional una sanción legislativa o una acción de un Ejecutivo electo, tuerce la voluntad de los representantes del pueblo real de aquí y ahora (...). El control judicial pertenece a una pecera diferente de la democracia, y esa es la razón de que se pueda hacer la acusación de que el control judicial es antidemocrático", The Least Dangerous Branch. The Supreme Court and the Bar of Politics, Yale University Press, New Haven, 1962, pp. 16 y ss.

${ }^{27}$ MAHRENHOLZ, Ernst G., "Verfassungsinterpretation aus praktischer Sicht", en Verfassungsrecht zwischen Wissenschaft und Richterkunst, Kolloquium aus Anlass des 70. Geburtstags von Konrad Hesse, Schnei- 
VI. Fuerza expansiva de los Derechos Fundamentales y control JURISDICCIONAL DE LA LIBERTAD DE CONFIGURACIÓN NORMATIVA DEL LEGISLADOR: UN EQUILIBRIO PROBLEMÁTICO

Las constituciones actuales no solamente se limitan a establecer barreras y regular procedimientos, sino que contienen objetivos definidos, así como los correspondientes parámetros de actuación y, por lo tanto, deben adentrarse mucho más en la realidad social que sus predecesoras liberales ${ }^{28}$. En el contexto del Estado social y democrático de derecho, la Constitución ha de cumplir la nueva función de mantener la vinculación jurídica de las decisiones políticas y administrativas dentro del marco de los sistemas de dirección, distribución y prestaciones, así como la de preservar la libertad material en virtud de los Derechos Fundamentales garantizados. De este modo, además de establecer un ordenamiento marco mediante el que se determinan las reglas democráticas a seguir en aras de una confrontación política ordenada y en libre competencia, incorpora asimismo el fundamento de unos principios básicos en orden a la convivencia de los individuos, las garantías de los elementos esenciales institucionales y el sistema de valores que, en tanto que consenso básico, confiere continuidad y estabilidad a la comunidad política.

Ahora bien, en el respeto de tales parámetros, corresponde al órgano legislativo la prerrogativa de la decisión en orden a la activación responsable de ese contenido constitucional aludido, dada su condición de intérprete primero y directo de la Constitución, esto es, la adopción de decisiones esenciales en confrontación viva y directa con la opinión pública. En este sentido, el Tribunal Constitucional español ha hecho referencia en muy diversas oportunidades a la libertad de configuración política que es propia del Legislador tocante al desarrollo de los compromisos constitucionales, a quien compete la creación primaria de Derecho con libertad en el marco ofrecido por la Norma Fundamental y no la mera ejecución de ésta ${ }^{29}$. Y, asimismo, ha expresado que no tiene él por función averiguar si la interpretación realizada por el legislador es la más coherente con la voluntad del poder constituyente objetivada en la Constitución ${ }^{30}$.

der, Hans-Peter y Steinberg, Rudolf (comps), C.F. Müller, Heidelberg, 1990, p. 58. En una dirección no distante pueden verse las consideraciones de ALEXY, Robert, "Ponderación, control de constitucionalidad y representación", en Teoría del discurso y derechos constitucionales, Cátedra Ernesto Garzón Valdés 2004, Fontamara, México, 2005, pp. 102-103.

${ }^{28}$ Grimm, Dieter, Die Zukunft der Verfassung, Suhrkamp, Frankfurt am Main, 1991, p. 340.

${ }^{29}$ En este sentido, desde las SSTC 5/1981, de 13 de febrero, y 11/1981, de 8 de abril; o por ejemplo, en la STC 209/1987, de 22 de diciembre: "el legislador no ejecuta la Constitución, sino que crea Derecho con libertad dentro del marco que ésta ofrece".

${ }^{30}$ STC 108/1986, de 29 de julio. 
Con todo, conviene recordar que tratándose de la tarea configuradora de los Derechos Fundamentales, el legislador se sitúa frente a un ámbito jurídico definido cuyo contenido no puede alterar. Por consiguiente, al concretizar el derecho en cuestión, le está vedado actuar con eficacia constitutiva. De lo contrario, terminaría por desaparecer la vinculación material del legislador a los Derechos Fundamentales y pasaría a colocarse en la posición que es propia del poder constituyente, el poder a quien corresponde la función de delimitación constitucional abstracta del objeto, contenido, funciones y límites de los Derechos Fundamentales. Por ello, cuando el legislador se mueve en el ámbito normativo protegido por los Derechos Fundamentales y trata de configurarlos jurídicamente, no decide libremente sobre su contenido. Se ha dicho así por diversos autores españoles que, en realidad, la Constitución "prefigura y el legislador configura"; si bien, reconociendo al mismo tiempo que, tratándose de Derechos Fundamentales, el empleo de estos conceptos no está exento de riesgo. Quizá por ello se entienda tal colaboración internormativa en el sentido de que la función configuradora llevada a cabo por el legislador, aun cuando sea una actividad integrada en el propio orden constitucional y condicionada exclusivamente por éste, tiene un carácter puramente subordinado y auxiliar, toda vez que sólo viene vía interpretativa a describir su significado y alcance jurídico-constitucional, esto es, un haz de facultades y poderes ya preexistentes $^{31}$. Como ha expresado el Tribunal Constitucional español, "el tipo abstracto de un derecho (...) preexiste conceptualmente al momento legislativo"32. Y éste puede ser, asimismo, el sentido atribuible a las declaraciones del propio Tribunal Constitucional español desde las que se recuerda la obligación de confrontar las normas legales "con otras de superior rango en cuanto definitorias de derechos fundamentales" ${ }^{\prime \prime 3}$, así como su insistencia acerca de la necesidad de interpretar las leyes conforme a la mayor efectividad de los mismos, de los que, obviamente, ha destacado su eficacia directa en cuanto vinculan a todos los poderes públi$\cos ^{34}$. Porque, "la libertad, viene a garantizar un ámbito de autonomía personal, y por tanto, también el ejercicio con pleno poder de autodeterminación de las facultades que componen esa específica manifestación de la libertad"35; haz de

\footnotetext{
${ }^{31}$ Evidentemente, de carácter limitado, como consecuencia de la cualidad jurídica de los derechos fundamentales, véase MülleR, Friedrich, Die Positivität der Grundrechte. Fragen einer praktischen Grundrechtsdogmatik, $2^{a}$ Edición, Dunker Humblot, Berlin, 1990, p. 41. Que ningún derecho constitucional es ilimitado se afirma en la STC 11/1981, de 8 de abril: "ningún derecho, ni aun los de naturaleza o carácter constitucional, pueden considerarse como ilimitados"; $y$ en el mismo sentido, por ejemplo, las SSTC 2/1982, de 29 de enero, o 120/1990, de 27 de junio.

${ }^{32}$ STC 11/1981, de 8 de abril.

${ }^{33}$ STC 37/1988, de 3 de marzo.

${ }^{34}$ STC 80/1982, de 20 de diciembre.

${ }^{35}$ STC 244/1991, de 16 de diciembre.
} 
facultades que integra precisamente, reiteramos, el contenido constitucional de los derechos, y que ha de ser respetado por el legislador al concretar la inicial definición constitucional abstracta en el momento del desarrollo (artículo 81.1 CE) e incluso en el de la regulación del ejercicio (artículo 53.1 CE) del respectivo derecho ${ }^{36}$, tareas ambas reservadas por la Constitución a la ley.

Por tanto, el legislador, sobre quien pesa "fundamentalmente la obligación de realizar los Derechos fundamentales en la vida de la comunidad política" ${ }^{\prime \prime 3}$, dispone de un margen de maniobra procedente del mandato democrático que le ha sido conferido, con el límite siempre de que su intervención no resulte desproporcionada: "el legislador, dentro de su libertad de elección, pero dentro de los límites constitucionales (...) tiene un amplio margen de libertad que este Tribunal ni puede ni debe restringir ${ }^{\prime \prime 38}$. Sin embargo, la libertad de configuración del legislador no tiene carácter absoluto sino limitado y, además, es heterogénea, es decir, tampoco es exactamente igual en todos los ámbitos, sino que se gradúa de acuerdo con la especificidad del respectivo ámbito material a regular. En efecto, sólo corresponde al legislador la tarea de decidir de una u otra manera en el ámbito de las alternativas conforme con la Constitución -libertad de la formación democrática de la voluntad--, en cuanto ésta, como ya hemos recordado, configura un "marco de coincidencias suficientemente amplio como para que dentro de él quepan opciones políticas de muy diferente signo", pero tales opciones políticas y de gobierno "no están previamente programadas de una vez por todas, de manera tal que lo único que cabe hacer en adelante es desarrollar ese programa previo" ${ }^{\prime 39}$. En consecuencia, atendiendo a lo dispuesto por la Constitución y a "los postulados básicos de un criterio democrático de legitimidad en la organización del Estado (...) (el) legislador goza, dentro de los límites establecidos en la Constitución, de un amplio margen de libertad que deriva de su posición constitucional y, en última instancia, de su específica legitimidad democrática"40,

\footnotetext{
${ }^{36}$ En la STC 11/1981, de 8 de abril, diría: “Corresponde (...) al legislador ordinario, que es el representante en cada momento histórico de la soberanía popular, confeccionar una regulación de las condiciones de ejercicio del derecho, que serán más restrictivas o abiertas, de acuerdo con las directrices políticas que le impulsen, siempre que no pase más allá de los límites impuestos por las normas constitucionales concretas y del límite genérico del Art. 53".

37 STC 53/1985, de 11 de abril.

${ }^{38}$ STC 37/1988, de 3 de marzo. Asimismo argumentando a partir de la naturaleza de la cosa y el amplio margen de apreciación que ha de corresponder al legislador, entre otras, SSTC 113/1994, de 14 de abril; 179/1994, de 16 de junio; 107/1996, de 12 de junio.

${ }^{39}$ STC 11/1981, de 8 de abril: "La labor de interpretación de la Constitución no consiste necesariamente en cerrar el paso a las opciones o variantes imponiendo autoritariamente una de ellas. A esta conclusión habrá que llegar únicamente cuando el carácter unívoco de la interpretación se imponga por el juego de los criterios hermenéuticos".
}

${ }^{40}$ STC 55/1996, de 28 de marzo. 
correspondiendo al Tribunal Constitucional en "un sistema de pluralismo político (Art. $1^{\circ}$ de la Constitución) la función de (...) fijar los límites dentro de los cuales pueden plantearse legítimamente las distintas opciones políticas" ${ }^{\prime 41}$.

Ahora bien, en la lógica del Estado constitucional, el propio Parlamento viene obligado a responder ante otra institución de sus decisiones, lo que llevaría a la institucionalización en el constitucionalismo continental de los tribunales constitucionales como órganos específicos de control del legislador. En efecto, el legislador no asume responsabilidad alguna respecto de su elección política y sus finalidades, pero sí en todo cuanto se refiere al respeto objetivo de las reglas expresadas por el Derecho constitucional, así como en lo relativo a los criterios valorativos del contenido de la legislación producida: "en un plano hay que situar las decisiones políticas y el enjuiciamiento político que tales decisiones merezcan y en otro plano la calificación de inconstitucionalidad, que tiene que hacerse con arreglo a criterios estrictamente jurídicos" ${ }^{\prime \prime 2}$. De esta forma, la legitimación del Tribunal Constitucional reside en la propia lógica del Estado constitucional, que se convierte así en un Estado constitucional de configuración específica -Verfassungsstaat spezifischer Prägung ${ }^{43}$-. Con todo, a diferencia de la libertad de configuración política del legislador como intérprete primero de la Constitución obviamente en el marco de ésta, al llevar a cabo el control de constitucionalidad, el Tribunal Constitucional no se encuentra suspendido en el vacío (J. Isensee), no puede dar rienda suelta a la imaginación interpretativa, sino que, desde un principio, se halla sometido a la restricción que le impone la decisión previa del legislador. Y su tarea no consiste en llegar a un resultado óptimo, sino en verificar si la ley contradice la Constitución o si aún es válida gracias a las tolerancias interpretativas que se ha ido construyendo, porque el Tribunal Constitucional no está realmente por encima del legislador, aunque tenga la última palabra en cuestiones constitucionales. En términos de precisión del correcto orden funcional, debe insistirse en que el monopolio jurisdiccional del Tribunal Constitucional es meramente de rechazo, esto es, de expulsión de las leyes que contradigan la Constitución, pero no de cualquier aplicación de la misma, porque, como se desprende con meridiana nitidez del Art. $163 \mathrm{CE}$, "todos los jueces y Tribunales deben aplicar e interpretar la Constitución"; de igual modo, resulta claro que cualquier aplicación de la ley requiere un juicio

\footnotetext{
${ }^{41}$ STC 4/1981, de 2 de febrero.

${ }^{42}$ STC 11/1981, de 8 de abril; STC 75/1983, de 3 de agosto: "no es función de este Tribunal Constitucional formular juicios técnicos, ni tampoco de mera oportunidad, acerca de los actos y disposiciones del poder público".

${ }^{43}$ Badura, Peter, "Arten der Verfassungsrechtssätze", en Isensee, Josef; KIRChHOF, Paul (Comps.), Handbuch des Staatsrechts der Bundesrepublik Deutschland, Bd. VII, C.H. Müller, Heidelberg, 1992, pp. 33 y ss.
} 
previo de constitucionalidad de carácter positivo por parte de los órganos judiciales. En definitiva, preservar la supremacía y normatividad de la Constitución es una responsabilidad compartida por todos los órganos constitucionales. E importa recordar cómo el criterio de corrección funcional -funktionell-rechtliche Richtigkeit- exige del órgano de interpretación suprema que se mantenga ineludiblemente en el ámbito de las funciones a él encomendadas, aunque es innegable el peligro siempre latente de que el Tribunal traspase la línea y se extralimite más allá de los cometidos jurídico-constitucionales que integran el ámbito de sus competencias invadiendo el propio de las que corresponde al Legislativo ${ }^{44}$.

En todo caso, si bien al Tribunal Constitucional le corresponde una función de control sin que le quepa inmiscuirse en la libertad conformadora del legislador, también es admitida de manera prácticamente unánime la innegable dificultad para definir una "barrera estricta", válida con carácter general, respecto de la actividad controladora desarrollada por el Tribunal Constitucional, sobre manera cuando de Derechos Fundamentales se trata. No obstante, aunque la "línea determinante para una definición" nunca va a ser simple, es posible inferirla con cierta claridad "del régimen de funciones de la Constitución" 45 ; rechazando así aquellas opiniones desde las que se acusa al Tribunal Constitucional de actuar como un legislador superior o de practicar el activismo judicial poniendo en peligro la estructura constitucional que él mismo está llamado a proteger (J. Isensee). En fin, la densidad de control y el margen de configuración del Legislador se condicionan recíprocamente: a la diferente amplitud del margen de configuración legislativa le corresponde una específica densidad de control a la hora de realizar el análisis de constitucionalidad. Con todo, no es posible resolver definitivamente la delimitación entre la jurisdicción constitucional y la legislación únicamente con criterios racionales. La vinculación constitucional de la legislación y el reconocimiento del derecho de ejercer el control constitucional de la misma, como señala $P$. Badura, se hallan estructuralmente en un "equilibrio inestable" -labiles Gleichgewicht-; pero se trata de un equilibrio a realizar y recomponer día tras día. En este esfuerzo delimitador, una de las primeras sentencias del Tribunal Constitucional español aludida hace unas líneas, determinó que en un sistema de pluralismo político la función que a él le corresponde es la de "fijar los límites dentro de los cuales pueden plantearse legítimamente las distintas opciones políticas" ${ }^{\prime \prime 6}$, y, en consecuencia, la tarea

\footnotetext{
${ }^{44}$ El control de constitucionalidad de las leyes debe ejercerse, dirá STC 14/2000, de 13 de abril, "de forma que no imponga restricciones indebidas al Poder Legislativo y respete sus opciones políticas".

${ }^{45}$ HESSE, Konrad, "Estadios en la historia de la jurisdicción constitucional alemana", Teoría y Realidad Constitucional núm. 1, 1998, p. 112.

${ }^{46}$ STC 4/1981, de 2 de febrero.
} 
interpretativa "de la Constitución no consiste necesariamente en cerrar el paso a las opciones o variantes imponiendo autoritariamente una de ellas. A esta conclusión habrá que llegar únicamente cuando el carácter unívoco de la interpretación se imponga por el juego de los criterios hermenéuticos. Queremos decir que las opciones políticas y de gobierno no están previamente programadas de una vez por todas, de manera tal que lo único que cabe hacer en adelante es desarrollar ese programa previo ${ }^{\prime \prime 4}$. Además, ha rechazado que su actividad tenga naturaleza legislativa, pues vendrá sistemáticamente afirmando que su condición no es la de legislador, sino la de "intérprete supremo de la Constitución", y, en consecuencia, que "sólo cabe solicitar de él el pronunciamiento sobre la adecuación o inadecuación de los preceptos a la Constitución" ${ }^{\prime 48}$. En última instancia, pues, el carácter de intérprete supremo de la Constitución atribuible al Tribunal Constitucional no pretende sino preservar la línea de separación entre el poder constituyente y los poderes constituidos. Expresiva de esta línea, la STC 76/1983, de 5 de agosto, precisa en el sentido de que corresponde al Tribunal Constitucional, "en su función de intérprete supremo de la Constitución (Art. 1 LOTC), custodiar la permanente distinción entre la objetivación del poder constituyente y la actuación de los poderes constituidos, los cuales nunca podrán rebasar los límites y las competencias establecidos por aquél"; idea que concuerda con lo expresado por $R$. Dworkin y su justificación de la necesidad de la justicia constitucional a la que el constituyente encomienda velar por las pre-condiciones de la democracia ${ }^{49}$.

En todo caso, lo anteriormente afirmado no ha impedido que determinados autores, como son los casos significativos de E. W. Böckenförde y B. Schlink en la doctrina continental europea, lleguen a observar que la competencia para interpretar la Constitución residenciada en el Tribunal Constitucional como intérprete último y auténtico, se va transformando sin solución de continuidad

\footnotetext{
${ }^{47}$ STC 11/1981, de 8 de abril.

${ }^{48}$ STC 5/1981, de 13 de febrero. En congruencia, dirá que su función es la de garantizar la libertad de acción política del legislador y el lugar privilegiado que ocupa la Ley en un Estado social y democrático de Derecho, "cuyos órganos legislativos son la representación del pueblo (Art. 66 de la Constitución)"; y que la ley "sólo puede ser en principio derogada o modificada por los representantes de esa voluntad, y sólo para el caso de que el precepto legal infrinja la Constitución se ha concedido a este Tribunal la potestad de anularla. Esta potestad únicamente podrá ser utilizada, sin embargo, cuando así lo exigen razones muy graves y sólidas; cuando un órgano constitucional o parte sustancial de él afirman la existencia de esa infracción, o cuando, de no ser declarada dicha infracción, un órgano judicial hubiera de verse en la situación de violar la Constitución porque, estando sometido al imperio de la ley (Art. 117.1 de la Constitución), carece de facultades para inaplicarla aunque la considere contraria a una norma más alta, pero anterior en el tiempo. Cuando estas razones sólidas y graves no existen, el respeto al legislador exige que este Tribunal se abstenga de hacer pronunciamiento alguno" (STC 17/1981, de 1 de junio).

${ }^{49}$ Dworkin, Ronald, Freedom's Law: the Moral reading of the American Constitution, Harvard University Press, Harvard, 1996.
} 
en una competencia para modificar la Constitución ${ }^{50}$, algo que no tenemos por exactamente preciso. Es la misma Constitución la que inevitablemente cambia de contenido de manera progresiva y paulatina -baste recordar su estructura dinámica, programática y fragmentaria-, a cuyo permanente cambio, naturalmente, el Tribunal Constitucional también contribuye por medio de su interpretación vinculante; dicho de otro modo, la jurisdicción constitucional, con el texto de la Constitución como límite, contribuye de forma decisiva a la configuración progresiva -concreción y actualización- del ordenamiento constitucional en su conjunto. En efecto, la Constitución ha de ser capaz de realizar el consenso fundamental de la sociedad pluralista, y constituye una obligación tanto por parte de los órganos del Estado como por parte de los ciudadanos, dentro de sus respectivas posibilidades, lograr que la Constitución se renueve y confirme en la conciencia de la comunidad política; teniendo en cuenta, eso sí, que la Constitución normativa está siempre dependiente del "principio de la relatividad", esto es, condicionada y relacionada con las fuerzas que forman y sostienen al Estado, si bien, las relaciones de poder no son el contenido sino el objeto de la Constitución normativa. En estas circunstancias, la tarea de aplicación/interpretación en materia constitucional adquiere el mayor grado de relevancia, y se trata de un "proceso" al que le resulta imposible ignorar esta realidad siempre dinámica sobre la que la Constitución se fundamenta. De lo contrario, más tarde o más temprano se descubrirá que la vida de la comunidad política no encuentra correspondencia en la norma e irá por sus propios derroteros. Lo cual no implica desconocer la advertencia que el propio $E$. $W$. Böckenförde había hecho, en el sentido de que si se entienden los Derechos Fundamentales "como normas (objetivas) de principio y se desarrollan como tales, es inevitable la progresión continua hacia el Estado jurisdiccional de justicia constitucional" ${ }^{51}$. Para que esta tendencia tuviera el carácter "irresistible" señalado por el autor, sería preciso, como señala $R$. Alexy, que la "expansión de los derechos constitucionales, definidos por la ubicuidad, la optimización y los derechos de prestación, implicara de hecho que todas y cada una de las normas y decisiones jurídicas se encontrasen ya contenidas en la Constitución, lo que

\footnotetext{
${ }^{50}$ BÖCKENFÖRDE, Ernst-Wolfgang, Estudios sobre el Estado de Derecho y la democracia, Trotta, Madrid, 2000, p. 193. En otros momentos presentó la imagen de una "continua reestructuración del complejo constitucional a favor de un poder jurisdiccional-constitucional", expresando el temor de un "cambio fundamental de la relación entre legislador y jurisdicción constitucional", traslación paulatina que trae su causa principalmente de la ampliación de funciones de los Derechos Fundamentales. De este modo, el Tribunal Constitucional se convierte en el órgano político más potente (no político-partidista), ante lo que se pregunta si serán igual de importantes o más importantes las elecciones de jueces del Tribunal Constitucional que las elecciones al parlamento nacional o regional 1990, pp. 1 y ss. En similares términos, SCHLINK, Bernard (1984): 457 y ss.

${ }^{51}$ BÖCKENFÖRDE, Ernst-Wolfgang, Escritos sobre Derechos fundamentales, Nomos, Baden-Baden, 1993, p. 135.
} 
daría lugar a la pérdida total de autonomía de la legislación parlamentaria y, en su virtud, también de toda competencia real"52, lo cual ya hemos visto carece de total verosimilitud. Cuestión distinta es la apuntada por F. Laporta, respecto de las consecuencias a las que abocaría una fuerte protección jurisdiccional de los derechos sociales, al compelir "al poder judicial a decidir explícita o implícitamente sobre la conformación y desarrollo del proceso de producción o distribución de recursos, y ello -dejando a un lado las cuestiones de eficiencia que plantearía esta más que discutible elaboración judicial del presupuestoentraría directa o indirectamente en contradicción con el principio democrático. Sería la superposición de ciertos derechos sociales al procedimiento democrático, el establecimiento de ciertos límites de política económica a la capacidad de sufragio como instrumento de diseño y puesta en práctica de un programa económico apoyado en la mayoría de los ciudadanos" ${ }^{\prime 53}$.

\section{BREVE APUNTE CRÍtICO ACERCA DE LA ÚlTIMA REFORMA DE LA ley orgánica del Tribunal Constitucional español en lo Referido al TRÁMITE DE ADMISIÓN DEL RECURSO DE AMPARO}

Por lo que se refiere a la experiencia constitucional española, ha sido decisiva la tarea del Tribunal Constitucional respecto de la consolidación del orden constitucional, y muy específicamente su contribución al establecimiento de un auténtico y eficaz sistema de Derechos Fundamentales. De esta suerte, de modo casi unánime, se estima que si el Recurso constitucional de Amparo ha terminado identificándose esencialmente en España con la protección de los Derechos Fundamentales, recíprocamente, la protección de los Derechos Fundamentales se identifica en líneas esenciales con el Recurso de Amparo. En consecuencia, tocante a la cautela con la que debe considerarse la subsidiariedad predicable en línea de principio del Recurso de Amparo, pueden verse los buenos argumentos apuntados por M. Carrasco, si bien termina reconociendo que la mayor parte de la doctrina científica española se ha inclinado a favor de la tesis de la subsidiariedad. Las distintas posiciones doctrinales respecto a una eventual regulación de carácter restrictivo tocante al trámite de admisión, así como sus reticencias al respecto, son bien sintetizadas también por este mismo autor, quien advirtiera acerca de que una eventual modificación de los criterios de admisión y de enjuiciamiento, no debería redundar "en merma de

\footnotetext{
${ }^{52}$ AleXY, Robert, "Sobre los Derechos Fundamentales a protección", en VV.AA., Derechos Fundamentales

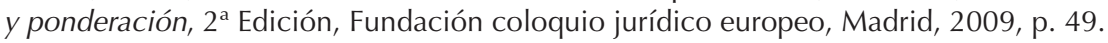

${ }^{53}$ LAPORTA, Francisco, "Los derechos sociales y su protección jurídica: introducción al problema", en Betegón, Jerónimo; Laporta, Francisco; De Páramo, Juan Ramón; Prieto Sanchís, Luis (Comps.), Constitución y derechos fundamentales, CEPYC, Madrid, 2004, p. 317.
} 
la tutela jurisdiccional de los Derechos Fundamentales" ${ }^{\prime 24}$. Y al referirse a la superioridad del Recurso de Amparo sobre los procesos ante órganos constitucionales, entre otros aspectos, destaca que esta condición se hace efectiva a través de dos mecanismos: "a) la eficacia correctora del recurso de amparo (...); y b) la auctoritas que confiere a la jurisprudencia del Tribunal Constitucional su condición de máximo órgano jurisdiccional en materia de interpretación de la Constitución, y, en particular, en lo relativo a garantías constitucionales o derechos fundamentales" ${ }^{\prime \prime 5}$.

Pues bien, expresado esto, vamos a realizar a continuación un breve comentario crítico acerca de la última reforma de la LOTC, en lo referente a las causas de inadmisión del Recurso de Amparo, a buen seguro, el aspecto más trascendental de la modificación llevada a cabo por medio de la Ley Orgánica 6/2007, de 24 de mayo, bajo la capa una vez más pretendidamente "racionalizadora": reordenar "la dedicación que el Tribunal otorga a cada una de sus funciones para cumplir adecuadamente con su misión constitucional", en los términos de la exposición de motivos.

Tocante a los requisititos de admisión, la reforma ha añadido un último inciso al primer apartado del Art. 49 de la LOTC, e incorporado un cuarto apartado nuevo. Vamos a dejarlo en razones de cortesía para no alargar demasiado esta aportación, y limitarnos a hacer algún breve apunte respecto del añadido al núm. 1 del actual Art. 49 que constituye ahora su último inciso: "En todo caso, la demanda justificará la especial trascendencia constitucional del recurso", lo que nos anuncia la modificación más trascendente operada, y apunta a la idea recurrente de endurecer el trámite de admisión. El planteamiento se desarrollaría como sigue: la especial trascendencia constitucional "se apreciará atendiendo a su importancia para la interpretación de la Constitución, para su aplicación o para su general eficacia y para la determinación del contenido y alcance de los derechos fundamentales" (art. 50.1.b de la LOTC) ${ }^{56}$.

En consecuencia, a tenor de la nueva formulación, ipuede minimizarse el alcance de la reforma bajo el argumento de que la idea ya estaba implícita en la causa de inadmisión por carencia manifiesta de contenido constitucional del anterior Art. 50.1.c de la LOTC? En nuestra opinión, la reforma ha abierto un portillo que permite ir bastante más lejos de lo ya permitido por el antiguo Art. 50.1.c de la LOTC, y desde luego eliminar a limine los recursos de amparo de "escasa" relevancia, pero, al fin y al cabo, de relevancia y lesión de naturaleza

${ }^{54}$ Carrasco Durán, Manuel, "El concepto constitucional de recurso de amparo", Revista Española de Derecho Constitucional, núm. 63, 2001, p. 125.

${ }^{55}$ Carrasco, "El concepto", cit. nota n. 54, pp. 104-105.

${ }^{56}$ Para un análisis completo de la problemática, remitimos a la obra de HeRnÁndez RamOS, Mario, El nuevo trámite de admisión del recurso de amparo constitucional, Reus, Madrid, 2009. 
constitucional, ¿y ésta puede ser escasa? Todo lo cual, nos parece sensiblemente distinto de la inadmisión por falta de "contenido constitucional" (previa regulación), en cuanto ahora se exige la concurrencia de dos requisitos: lesión de un Derecho Fundamental, y especial trascendencia constitucional de la misma ${ }^{57}$.

De otra parte, asimismo, cabe preguntarse si la reforma va a terminar convirtiendo al Tribunal Constitucional español en un tribunal de casación constitucional en materia de Derechos Fundamentales, como entendemos indisimuladamente se ha pretendido, y nos atrevemos a responder en sentido de que se nos permita como mínimo expresar serias dudas. El problema del manido "atasco" y del retraso más allá de lo razonable en resolver por parte del Tribunal Constitucional, es de carácter estructural. En consecuencia, la cuestión es más compleja, y precisa de diagnosticar bien el problema para luego tener posibilidades de acertar en la solución. Porque, más que probablemente, no hace falta ser en exceso perspicaces para advertir que el aluvión de Recursos de Amparo ante el Tribunal Constitucional trae causa del deficiente funciona-

\footnotetext{
${ }^{57}$ Expresiva la STC 155/2009, de 25 de junio: "La demanda ha sido promovida tras la entrada en vigor de la Ley Orgánica 6/2007, de 24 de mayo, por la que se modifica la Ley Orgánica 2/1979, de 3 de octubre, del Tribunal Constitucional (LOTC), de modo que su interposición, admisión a trámite, tramitación y resolución se rigen por la nueva regulación del recurso de amparo llevada a cabo por la citada Ley Orgánica 6/2007, de 24 de mayo. Constituye el elemento más novedoso o la 'caracterización más distintiva' (ATC 188/2008, de 21 de julio, FJ 3) de esta regulación del recurso de amparo el requisito sustantivo o de fondo de la 'especial trascendencia constitucional' que impone el art. 50.1 b) de la LOTC para la admisión del recurso. En él se plasma la opción del legislador, en el ejercicio de la habilitación que constitucionalmente le confiere el art. 161.1 b) de la CE, en relación con su art. 53.2 , por una nueva configuración del recurso de amparo, toda vez que, en principio, tras la reforma llevada a cabo la mera lesión de un derecho fundamental o libertad pública tutelable en amparo ya no será por sí sola suficiente para admitir el recurso, pues es imprescindible, además, su 'especial trascendencia constitucional', frente a la configuración por la que esencialmente se caracterizaba en su anterior regulación, en tanto que recurso orientado primordialmente a reparar las lesiones causadas en los derechos fundamentales y libertades públicas del demandante susceptibles de amparo. Así pues, para la admisión del recurso de amparo no es suficiente la mera lesión de un derecho fundamental o libertad pública del recurrente tutelable en amparo [arts. 53.2 y 161.1 b) de la CE y 41 de la LOTC], sino que además es indispensable, en lo que ahora interesa, la especial trascendencia constitucional del recurso [art. 50.1 b) de la LOTC] (....) Aunque el recurrente ha de satisfacer necesariamente, de acuerdo con lo dispuesto en el art. 49.1 in fine de la LOTC, la carga de justificar en la demanda la especial trascendencia constitucional del recurso (AATC 188/2008, de 21 de julio; 289/2008 y 290/2008, de 22 de septiembre), es a este Tribunal a quien corresponde apreciar en cada caso la existencia o inexistencia de esa 'especial trascendencia constitucional'; esto es, cuándo, según el tenor del art. 50.1 b) de la LOTC, 'el contenido del recurso justifique una decisión de fondo por parte del Tribunal Constitucional en razón de su especial trascendencia constitucional', atendiendo para ello a los tres criterios que en el precepto se enuncian: 'a su importancia para la interpretación de la Constitución, para su aplicación o para su general eficacia y para la determinación del contenido y alcance de los derechos fundamentales'. El carácter notablemente abierto e indeterminado, tanto de la noción de 'especial trascendencia constitucional', como de los criterios legalmente establecidos para su apreciación, confieren a este Tribunal un amplio margen decisorio para estimar cuándo el contenido de un recurso de amparo 'justifica una decisión sobre el fondo (...) en razón de su especial trascendencia constitucional'".
} 
miento de la tutela jurisdiccional ordinaria; y una buena prueba de ello la ofrece el hecho de que la gran mayoría de los recursos de amparo se interponen por vulneración presunta del Art. 24 de la CE (derecho a la tutela judicial efectiva). Ahora bien, cuando el ciudadano observa que unos mismos hechos son tratados de diferente manera por distintos juzgados, la presentación de Recursos de Amparo ante el Tribunal Constitucional y la obtención como resultado de que unos sean atendidos y otros no, delatará una arbitrariedad inexcusable, siendo así que el Recurso de Amparo constituye una protección reforzada (más que subsidiaria) de los Derechos Fundamentales. Por ello, si cada vez en superior medida los jueces actúan según su criterio, o tienen posibilidad, sin atenerse a una directriz común que nivele y establezca un sentido equitativo por el cual guiarse, la generalización del caos ya importante existente, puede convertirse en una realidad incuestionable.

En estas coordenadas, mientras la situación siga así, las peticiones de Amparo constitucional y la presión para el órgano, seguirán aumentando ${ }^{58}$, pues, por las razones que sea, la litigiosidad ordinaria también lo hace; continuamente se nos dice que los jueces no dan abasto, y tropezar con un Derecho Fundamental es sumamente fácil, dada la fuerza irradiadora aludida más arriba. Hay con todo una plus petición al Tribunal Constitucional, Ilegando, pues, a solicitar lo que no está previsto que nos pueda ofrecer, y negar esto sería poco honrado. Quizá se venga consiguiendo alguna agilización, pero los jueces constitucionales deben seguir ocupándose de determinar, en una escala ahora de "trascendencias", cuáles son de especial trascendencia constitucional y cuáles no; y aun acertando, la protección sólo será parcial, con lo cual, se habrá llevado a cabo una a su vez parcial desaparición del Recurso de Amparo constitucional bajo la capa de la siempre socorrida racionalización. En fin, si la respuesta a la cuestión de su permisibilidad por los Arts. 53.2 y 161.1.b de la CE, se pretende salvar reflexionando aisladamente acerca de qué significa semánticamente "en su caso", lo que permitiría interpretar que el Recurso de Amparo constitucional sólo es aplicable a determinadas lesiones de los Derechos Fundamentales, también nos parece cuando menos una harto discutible conclusión, y sobre todo triste. Porque, ¿no se estará optando aquí por una tutela limitada de los Derechos Fundamentales a tenor de las breves consideraciones que más arriba se han hecho sobre la virtualidad del Recurso de Amparo? Y si tal recurso pierde algunas de sus virtudes, estamos abriendo una puerta, más o menos amplia, pero no vemos que conduzca inevitablemente a más esperanza.

${ }^{58}$ En 2007 se interpusieron 9.840 Recursos de Amparo, 10.279 en 2008 y 10.792 en 2009. 


\section{Bibliografía}

AleXY, Robert, "Ponderación, control de constitucionalidad y representación", en Teoría del discurso y derechos constitucionales, Cátedra Ernesto Garzón Valdés 2004, Fontamara, México, 2005.

"Sobre los Derechos Fundamentales a protección", en VV.AA., Derechos Fundamentales y ponderación, $2^{a}$ Edición, Fundación coloquio jurídico europeo, Madrid, 2009.

Álvarez Conde, Enrique, Curso de Derecho Constitucional, Vol. II, 6a Edicón, Tecnos, Madrid, 2008

BADURA, Peter, "Die Verfassung im Ganzen der Rectsordung und die Verfassngskonkretisierung durch Gesetze", en ISENSEE, Josef; KIRChHOF, Paul (Comps.), Handbuch des Staatsrechts der Bundesrepublik Deutschland, Bd. VII. Heidelberg, C.H. Müller, 1992.

"Arten der Verfassungsrechtssätze", en ISENSEE, Jose; KIRCHHOF, Paul (Comps.), Handbuch des Staatsrechts der Bundesrepublik Deutschland, Bd. VII, C.H. Müller, Heidelberg, 1992.

BICKEL, Alexander, The Least Dangerous Branch. The Supreme Court and the Bar of Politics, Yale University Press, New Haven, 1962.

BÖCKENFÖRDE, Ernst-Wolfgang, Staat, Verfasung, Demokratie. Studien zur Verfassungstheorie und zum Verfassungsrecht, Suhrkamp, Frankfurt am Main, 1991. drid, 2000.

Staat, Verfasung, Demokratie. Studien zur Verfassungstheorie und zum Verfassungsrecht, Suhrkamp, Frankfurt am Main, 1991. 1993.

Carrasco Durán, Manuel, "El concepto constitucional de recurso de amparo", Revista Española de Derecho Constitucional, núm. 63, 200.

Cascajo Castro, José-Luis, La tutela constitucional de los derechos sociales, CEC, Madrid, 1988.

CHeL, Enzo, Il giudice delle leggi. La Corte costituzionale nella dinamica dei poderi, Il Mulino, Bologna, 1999.

DworkIN, Ronald, Freedom's Law: the Moral reading of the American Constitution, Harvard University Press, Harvard, 1996.

ForsthOFF, Ernst, "Die Umbildung des Verfassungsgesetzes", en BarION, Hans; FORSTHOFF, Ernst; WeBer, Werner (Comps.), Festschrift für Carl Schmitt 70 Geburtstag, Duncker \& Humbolt, Berlín, 1959.

Grimm, Dieter, Die Zukunft der Verfassung, Suhrkamp, Frankfurt am Main, 1991. 
Gusy, Christoph, "Die Verfassungsbeschwerde", en BAdura, Peter; Dreier, Horst (Comps.), Festschrift 50 Jahre Bundesverfassungsgericht, Bd. I. Tübingen, Mohr Siebeck, 2001.

HenNIS, Wilhelm, "Integration durch Verfassung?", Juristenzeitung, 1999.

Hernández Ramos, Mario, El nuevo trámite de admisión del recurso de amparo constitucional, Reus, Madrid, 2009.

Hesse, Konrad, Derecho Constitucional y Derecho Privado, Civitas, Madrid 1995.

, "Estadios en la historia de la jurisdicción constitucional alemana", Teoría y Realidad Constitucional, núm. 1, 1998.

Hillgruber, Christian, Der Schutz des Menschen vor sich selbst, Vahlen, München, 1992.

ISENSEE, Josef, "Bundesverfassungsgericht - Quo vadis?", Juritenzeitung, 1996.

KeLSEN, Hans, Reine Rechtslehre: Einleitung in die rechtswissenschaftliche Problematik, 2 ${ }^{a}$ Edición, Franz Deuticke, Wien, 1960

JARAS, Hans D., "Grundrechte als Wertentscheidungen bzw. objektiv-rechtliche Prinzipien in der Rechtsprechung des Bundesverfassungsgerichts", Archiv des öffentlichen Rechts núm. 110, 1985.

Kramer, Larry, The People Themselves, Oxford University Press, Oxford, 2004.

Laporta San Miguel, Francisco, "Los derechos sociales y su protección jurídica: introducción al problema", en BeTEGón, Jerónimo; LAPORTA, Francisco; De PÁramo, Juan Ramón; Prieto Sanchís, Luis (Comps.), Constitución y derechos fundamentales, CEPYC, Madrid, 2004.

LEISNER, Walter, Demokratie. Betrachtungen zur Entwicklung einer gefährdeten Staatsform, Duncker \& Humbolt, Berlín,1998.

LüBBE-WolfF, Gertrude, Grundrechte als Eingriffabwehrrechte, Nomos, BadenBaden, 1988.

Mahrenholz, Ernst G., "Verfassungsgerichtsbarkeit und Gesetzgebung", en Badura, Peter; Schloz, Rupert (Comps.), Verfassungsgerichtsbarkeit und Gesetzgebung, C.H. Beck, München,1998.

"Verfassungsinterpretation aus praktischer Sicht", en SCHNEIDER,

Hans-Peter; SteinberG, Rudolf (Comps.), Verfassungsrecht zwischen Wissenschaft und Richterkunst. Kolloquium aus Anlass des 70. Geburtstags von Konrad Hesse, C.F. Müller, Heidelberg, 1990.

Mendes, Gilmar-Ferreira, Jurisdição Constitucional, Saraiva, São Paulo, 1999, Müller, Friedrich, Die Positivität der Grundrechte. Fragen einer praktischen Grundrechtsdogmatik, 2a Edición, Dunker Humblot, Berlin, 1900.

Müller, Friedrich; Villacorta Mancebo, Luis-Quintín: 2008. Postpositivismo, TGD, Santander. 
Nogueira Alcalá, Humberto, Derechos fundamentales y garantías constitucionales, T. 1, 2ª Edición, Librotecnia, Santiago, 2008.

SCHLINK, Bernard, "Freiheit durch Eingriffsabwehr - Rekonstruktion der klassischen Grundrechtsfunktion", Europäische Grundrechte-Zeitschrift, 1984.

Schulze-Fielitz, Helmut, "Das Bundesverfassungsgericht und die öffentliche Mainung", en Schuppert, Gunnar-Folke; Bumke, Christian (Comps.), Bundesverfassungsgericht und gesellschaftlicher Grundkonsens, Nomos, BadenBaden, 2000.

Schмıтт, Carl, Legalität und Legitimität, $7^{\text {a }}$ Edición, Duncker \& Humbolt, Berlín, 1998.

SteRn, Klaus; SACHS, Michael, Das Staatsrecht der Bundesrepublik Deutschland, Vol. III/1, C.H. Beck, München, 1988.

Tushnet, Mark, Taking the Constitution Away from the Courts, Princeton University Press, Princeton, 1999.

WAHL, Rainer; WIELAND, Joachin, "La jurisdicción constitucional como bien escaso", Revista Española de Derecho Constitucional, núm. 51, 1997.

WAHL, Rainer; RotTMAnN, Frank, "Die Bedeutung der Verfassung und der Verfassungsgerichtsbarkeit in der Bundesrepublik - ein Vergleich zum 19. Jahrhundert und zu Weimar", en ConZE, Werner; Lepsius, M. Rainer (Edits.), Sozialgeschichte der Bundesrepublik Deutschland: Beiträge zum Kontinuitätsproblem, Klett-Cotta, Stuttgart, 1983.

Waldron, Jeremy, Derecho y desacuerdos, Marcial Pons, Madrid, 2005. 